MF

Publication 


\title{
Democratic Republic of the Congo: Poverty Reduction Strategy Paper- Progress Report
}

This poverty reduction strategy paper - progress report on the Democratic Republic of the Congo was prepared by the authorities of the Democratic Republic of the Congo as background documentation for the periodic consultation of the International Monetary Fund with the member country. It is based on the information available at the time it was completed in April, 2010. The views expressed in this document are those of the member country and do not necessarily reflect the views of the International Monetary Fund staff or the Executive Board of the IMF.

The policy of publication of staff reports and other documents by the IMF allows for the deletion of market-sensitive information.

Copies of this report are available to the public from

\author{
International Monetary Fund $\bullet$ Publication Services \\ $70019^{\text {th }}$ Street, N.W. $\bullet$ Washington, D.C. 20431 \\ Telephone: (202) 623-7430 • Telefax: (202) 623-7201 \\ E-mail: publications@imf.org Internet: http://www.imf.org
}

\section{International Monetary Fund \\ Washington, D.C.}


Democratic Republic of the Congo

Inter-Ministerial Commission on Implementation of the National Poverty Reduction Strategy CI-SNLCP

\section{REPORT ON IMPLEMENTATION OF THE GROWTH AND POVERTY REDUCTION STRATEGY}

April 2010 


\section{TABLE OF CONTENTS}

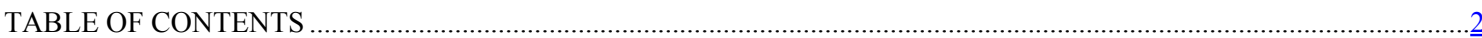

ACRONYMS

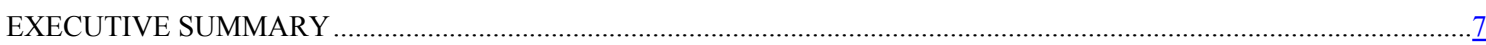

CONTEXT SURROUNDING THE PREPARATION AND IMPLEMENTATION OF THE FINAL GPRSP ...........................14

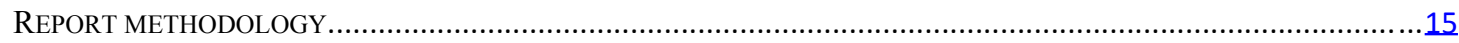

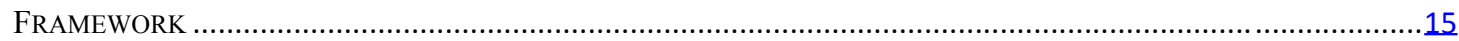

CHAPTER 1. ANALYSIS OF MACROECONOMIC PERFORMANCE AND EXPENDITURE......................... 17

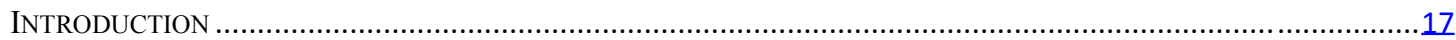

1.1. RECENT DEVELOPMENTS IN THE CONGOLESE ECONOMY …................................................................

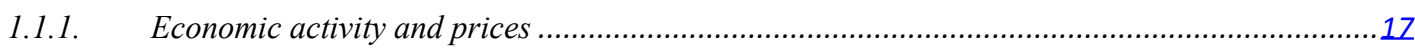

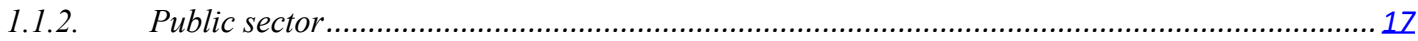

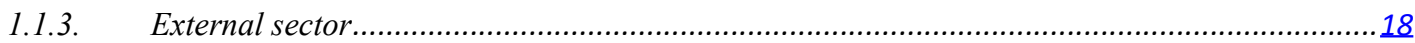

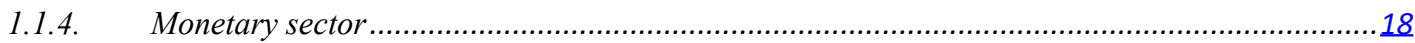

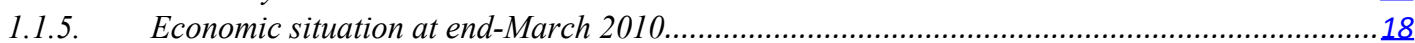

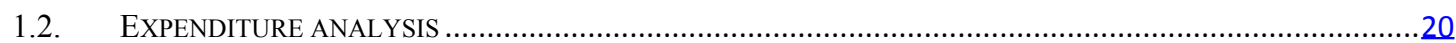

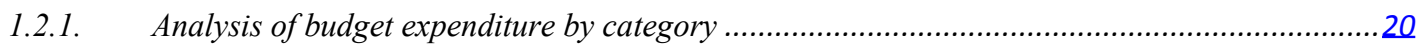

1.2.2. Public expenditure in relation to GPRSP priorities..................................................................

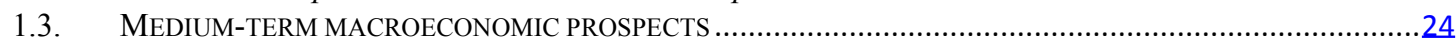

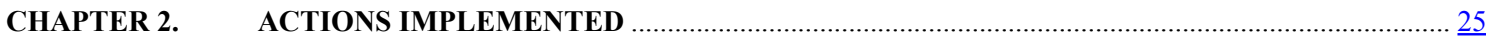

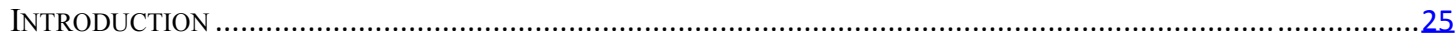

2.1. PROMOTING GOOD GOVERNANCE AND CONSOLIDATING PEACE THROUGH STRENGTHENED

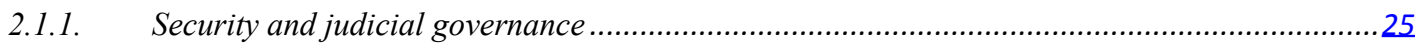

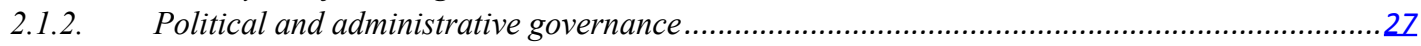

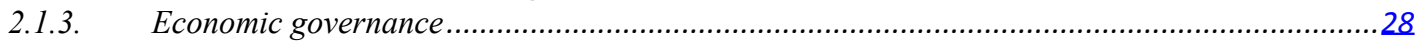

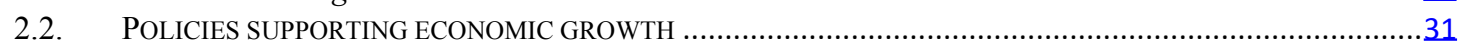

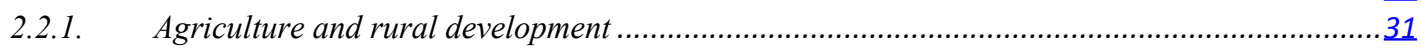

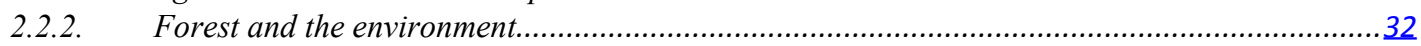

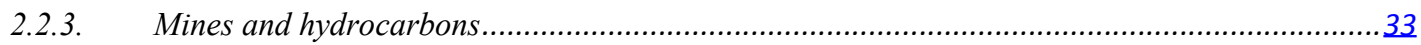

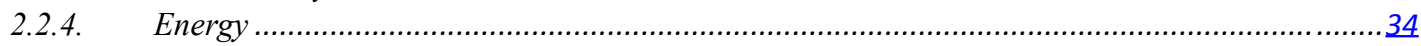

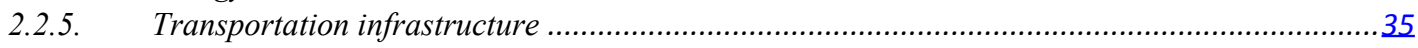

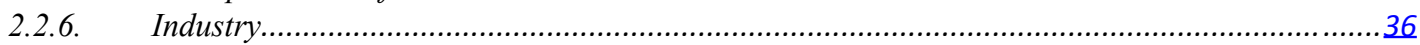

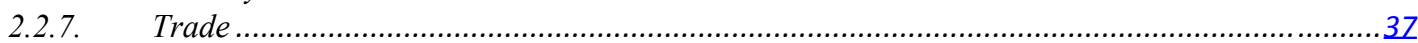

2.3. IMPROVED ACCESS TO BASIC SOCIAL SERVICES AND REDUCED VULNERABILITY ..................................37

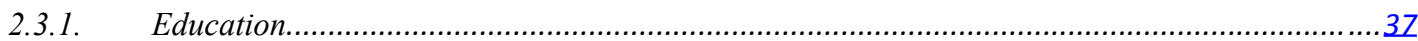

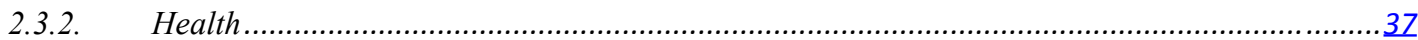

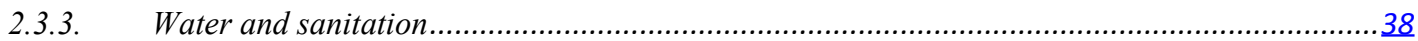

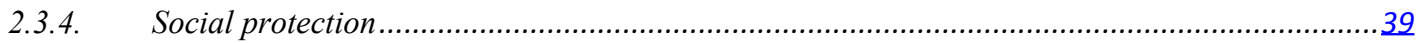

2.4. THE FIGHT AGAINST HIV/AIDS (ONE OF THE GPRS PILLARS) ………........................................

2.4.1. Preventing and stabilizing HIV and STI transmission …....................................................

2.4.2. Speeding treatment and improving the quality of life of persons living with HIV/AIDS .............41

2.4.3. Mitigating the socioeconomic impact of HIV/AIDS on the community ....................................1

2.4.4. Building coordination, monitoring and evaluation capacities at all levels ................................41

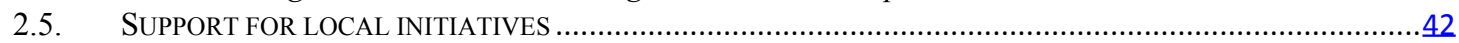

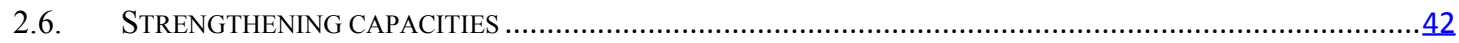

CHAPTER 3. MONITORING AND EVALUATION ……………………………….................................

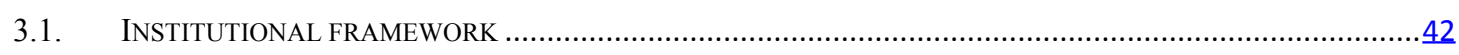

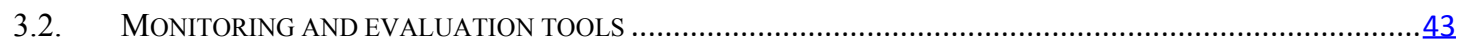




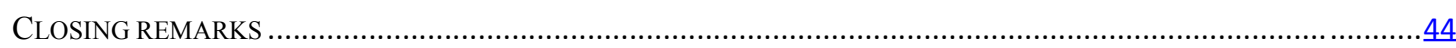

ANNEXES 


\section{ACRONYMS}

\begin{tabular}{|c|c|}
\hline AGT & Large-Scale Works Agency \\
\hline ASNIC & Intermediate and Central Health System Support \\
\hline ASNIP & Intermediate and Peripheral Health System Support \\
\hline $\mathrm{BCC}$ & Central Bank of the Congo \\
\hline CAMI & Mining rights administrator Cadastre minier \\
\hline CDF & Congolese francs \\
\hline CEEC & Expertise, Evaluation and Certification Center \\
\hline CI-SNLCP & $\begin{array}{l}\text { Inter-Ministerial Commission on Implementation of the National Poverty } \\
\text { Reduction Strategy }\end{array}$ \\
\hline CISPI & $\begin{array}{l}\text { Inter-Ministerial Monitoring Commission for Financial Institution } \\
\text { Programs }\end{array}$ \\
\hline CNDP & National Congress for Defense of the People \\
\hline CNMLS & National Multi-Sector Commission to Combat AIDS \\
\hline COREF & Steering Committee on Public Finance Reform \\
\hline CPCM & Standing Macroeconomic Framework Committee \\
\hline CSMOD & Strategic Decentralization Implementation Framework \\
\hline CSRP & Police Reform Monitoring Committee \\
\hline CTB & Belgian Technical Cooperation \\
\hline CTR & CISPI Technical Monitoring Committee \\
\hline DEVINFO & Human development database \\
\hline DGDA & Customs and Excise Directorate \\
\hline DGDP & Directorate of Public Debt \\
\hline DGE & DGDA Large Enterprises Department \\
\hline DGI & Tax administration \\
\hline DGRAD & Directorate of Administrative and State Revenues \\
\hline DPSB & Directorate of Planning and Budget Monitoring \\
\hline DPSI & Industrial Policy and Strategy Document \\
\hline DRC & Democratic Republic of the Congo \\
\hline DTO & Treasury Management and Payment Authorization Office \\
\hline DVDA & Agricultural Feeder Roads Department \\
\hline EDS & Demographic and health survey \\
\hline ESB & Budget monitoring reports \\
\hline FAO & United Nations Food and Agriculture Organization \\
\hline FINEXPO & Belgian Export Financing \\
\hline FONER & National Highway Maintenance Fund \\
\hline FSRDC & Social Fund of the Democratic Republic of the Congo \\
\hline GAVI & Global Alliance for Vaccines and Immunization \\
\hline GECAMINES & State-owned mining company Générale de Carrières et des Mines \\
\hline GMRRR & $\begin{array}{l}\text { Joint Discussion Group on Reform and Reorganization of the Congolese } \\
\text { National Police }\end{array}$ \\
\hline GPRS & Growth and poverty reduction strategy \\
\hline GPRSP & Growth and Poverty Reduction Strategy Paper \\
\hline GTZ & German Agency for Technical Cooperation \\
\hline HIPC & Heavily Indebted Poor Countries Initiative \\
\hline ICCN & Congolese Nature Conservation Institute \\
\hline IGT & Office of the Labor Inspector \\
\hline INERA & National Institute for Agronomy Research \\
\hline INS & National Institute of Statistics \\
\hline OI & Opportunistic Infection \\
\hline EITI & Extractive Industries Transparency Initiative \\
\hline
\end{tabular}




\begin{tabular}{|c|c|}
\hline JICA & Japan International Cooperation Agency \\
\hline MDG & Millennium Development Goals \\
\hline MDRI & Multilateral Debt Reduction Initiative \\
\hline MDRI & Multilateral Debt Reduction Initiative \\
\hline MICS & Multiple Indicator Cluster Survey \\
\hline MONUC & United Nations Mission to the Congo \\
\hline $\mathrm{NGO}$ & Nongovernmental organization \\
\hline NSS & National Statistics System \\
\hline$\overline{\mathrm{OCC}}$ & Ministry of Trade Inspection Office \\
\hline OCPI & Congolese Poverty and Inequality Observatory \\
\hline ODR & Highway Authority \\
\hline OFIDA & Customs and Excise Office [DGDA predecessor] \\
\hline OGEDEP & Public Debt Management Office [DGDP predecessor] \\
\hline OHADA & Organization for the Harmonization of Business Law in Africa \\
\hline OKIMO & Kilo Moto Gold Mining Office \\
\hline ONATRA & National Transportation Office \\
\hline ONEM & National Employment Office \\
\hline OVC & Orphans and vulnerable children) \\
\hline OVD & Road Network and Drainage Authority \\
\hline PAIDECO & Program in Support of Community Development Initiatives \\
\hline PAP & Priority Action Plan \\
\hline PARSAR & $\begin{array}{l}\text { Agricultural and Rural Sector Rehabilitation Support Project in Bandundu } \\
\text { and Bas-Congo Provinces }\end{array}$ \\
\hline PARSS & World Bank Health Sector Reform Project \\
\hline PASU & Emergency Social Action Project \\
\hline PEASU & Peri-Urban Water Supply and Sanitation Project \\
\hline PEMU & World Bank Urban Potable Water Supply Project \\
\hline PFCN & World Bank Forest and Nature Conservation Project \\
\hline PGAI & Aid and Investment Management Platform \\
\hline PIEGMA & Better Job Market Management through Effective Data Processing \\
\hline PMEDE & Domestic Electricity Markets for Consumption and Export Project \\
\hline PMUEIAA & Multi-Sector Socioeconomic Rehabilitation Project \\
\hline PMURIS & $\begin{array}{l}\text { Emergency Multi-Sector Socioeconomic Infrastructure Rehabilitation } \\
\text { Project }\end{array}$ \\
\hline PMURR & $\begin{array}{l}\text { Emergency Multi-Sector Infrastructure Rehabilitation and Reconstruction } \\
\text { Program }\end{array}$ \\
\hline PNC & Congolese National Police \\
\hline PNDS & National Health Development Program \\
\hline PNFOCO & National Forest and Nature Conservation Project \\
\hline PNMLS & National Multi-Sector Program against HIV/AID \\
\hline PRAPE & Equateur Province Agricultural Recovery Program \\
\hline PRAPO & Orientale Province Agricultural Recovery Program \\
\hline PRESAR & $\begin{array}{l}\text { Agriculture and Rural Sector Rehabilitation Project in Ktanga, West } \\
\text { Kasai and East Kasai Provinces }\end{array}$ \\
\hline PRGF & Growth and Poverty Reduction Facility \\
\hline PRODAP & Lake Tanganyika Integrated Regional Development Program \\
\hline PROMINES & Mining promotion project \\
\hline PRONAREC & National Capacity Strengthening Program \\
\hline PRSP-I & Interim Poverty Reduction Strategy Paper \\
\hline PS9FED & Ninth European Development Fund Health Program \\
\hline PSRFP & Strategic Plan for Public Finance Reform \\
\hline PURUS & Emergency Urban and Social Infrastructure Rehabilitation Project \\
\hline
\end{tabular}




\begin{tabular}{|l|l|}
\hline RAAAP & $\begin{array}{l}\text { Rapid Country Assessment, Analysis, and Action Planning Initiative on } \\
\text { Behalf of Orphans and other Vulnerable Children in Sub-Sahara Africa }\end{array}$ \\
\hline REGIDESO & Water Distribution Authority \\
\hline RVA & National Aviation Administration \\
\hline SAESSCAM & Small Scale Mining Support Department \\
\hline SAPMP & Southern Africa Power Market Project \\
\hline SENAREC & National Capacity Strengthening Secretariat \\
\hline SENASEM & National Seed Service \\
\hline SIE & Energy Information System \\
\hline SNCC & Congolese National Railroad Company \\
\hline SRSS & Health System Strengthening Strategy \\
\hline STI & Sexually transmitted infections \\
\hline TFP & Technical and financial partners \\
\hline UNAIDS & United Nations Programme on HIV/AIDS \\
\hline UNDP & United Nations Development Program \\
\hline UNGASS & United Nations General Assembly Special Session on HIV/AIDS \\
\hline UNICEF & United Nations Children's Fund \\
\hline UPPE-SRP & CI-SNLCP National Poverty Reduction Strategy Coordinating Unit \\
\hline USAID & United States Agency for International Development \\
\hline WHO & World Health Organization \\
\hline
\end{tabular}




\section{EXECUTIVE SUMMARY}

The Government of the Democratic Republic of the Congo (DRC) issues its report on the implementation of its Poverty Reduction and Growth Strategy Paper (GPRSP) for 2009, in the context of achieving completion point triggers under the enhanced initiative for Heavily Indebted Poor Countries (HIPC). The DRC aims to qualify for substantial external debt cancellation under both the HIPC Initiative and the Multilateral Debt Reduction Initiative (MDRI).

The GPRSP was prepared in two phases. In the first phase, an interim poverty reduction strategy paper (PRSP-I) was put in place for practical reasons relating notably to limitations of the statistical apparatus and weakened human and institutional capacities in formulating development policies, the delayed consequence of years of political, economic, and social instability. Through the successes of one year's implementation of the PRSP-I and six months' execution of the program supported by the Poverty Reduction and Growth Facility (PRGF), a key component of the PRSP-I, the DRC reached the decision point under the enhanced HIPC Initiative in July 2003 and was granted debt relief representing approximately $90 \%$ of the State's debt service, which was used to finance spending to combat poverty.

In the second phase, a final version of the poverty reduction strategy (which had since become the Growth and Poverty Reduction Strategy Paper, GPRSP) was developed through a participatory approach. The final version of the first-generation GPRSP was first adopted by the transition government in July 2006, and subsequently endorsed by the government elected through free and democratic elections in March 2007. It was approved by the World Bank Board of Directors and the IMF Executive Board in March and April, 2007, respectively. Following practical difficulties, the action plan for implementation of the first-generation GPRSP was finalized in July 2007.

It is important to recall that the implementation of the GPRSP beginning in July 2007 took place in an extremely challenging environment, marked by (i) the devastation of economic and social infrastructures, a formidable obstacle to private sector growth and development; (ii) uncertainties surrounding the preparation and staging of the first truly free and democratic elections in a climate of heightened tensions; (iii) renewed hostilities in the eastern region, bringing grave humanitarian consequences; (iv) the global food and energy crises; (v) the international financial crisis (the most serious since the Great Depression of 1929); (vi) the collapse in commodity prices and resultant contraction of government revenue; (vii) the lack of budgetary support since the 2006 suspension of the PRGF program; and (viii) weak human and institutional capacities, particularly in the areas of statistics, policy formulation, and the monitoring and evaluation of policy implementation.

The combination of these factors adversely affected the conduct of macroeconomic and sector policies.

Macroeconomic policies were implemented under the program supported by the Extended Credit Facility that took effect in July 2009 and was formally concluded in December 2009. The overall results were satisfactory. The economy grew by 2.8 percent, compared to a target of 2.7 percent, sparked by a third-quarter recovery in the mining sector and the attendant spillover effects in the tertiary sector. Inflation climbed to 53.4 percent, corresponding to an 
annual average of 46.1 percent, compared to a target of 48.7 percent. The indicative U.S. dollar-Congolese franc exchange rate was 902.7, representing a 29.2 percent depreciation compared to the same period of 2008.

This macroeconomic performance was the result of rigorous budgetary and monetary policies adopted in 2009 and pursued through third quarter 2010. Inflation declined from around 47.6 percent in February 2010 to 34.3 percent in March. In annualized terms, it stood at 19.6 percent in March compared to 50.9 percent in February and an annual target of 15 percent.

Viewed in terms of GPRSP pillars, public expenditure management demonstrates the importance of the strategic pillar "Promoting good governance and peace." Spending for this pillar accounted for roughly 60 percent of primary expenditure in 2009 , followed by pillar 3 , "Promoting access to basic social services," which declined slightly as a proportion of primary expenditure from 24.9 percent in 2008 to 23.6 percent in 2009. Pillar 2, "Support sectors with growth potential," increased from 16.2 percent in 2008 to 16.5 percent in 2009 .

The government recognizes that continued, sustainable growth in a stable macroeconomic climate is essential to reducing poverty. The medium-term macroeconomic objectives remain the same as agreed in the recent PRGF arrangement. Stated in quantitative terms, the objectives are: (i) reduce year-to-year inflation to 9 percent by end-2012; (ii) increase international reserves to 10 weeks of nonaid imports by end-2012; and (iii) achieve real GDP growth in the range of 6 percent per annum. The government intends to accelerate its program of reforms to achieve these objectives.

The accomplishments in regard to sector policies are highly encouraging. With respect to security, operations successfully reestablished peace and the government's authority in the eastern and western parts of the country (the Goma peace accord, the Amani Programme for the Security, Pacification, Stabilization and Reconstruction of the Kivu Provinces, the joint Umoja Wetu operation with Rwanda, Kimia I and II, Operation Amani Leo, and the assimilation (brassage), disarmament, demobilization, and integration of ex-combatants).

There was notable progress in the administration of justice, including review of the Ministry of Justice organizational framework, the new Constitutional Court act awaiting adoption by the Parliament, the construction of a new Palais de Justice, and rehabilitation of courthouses, prosecutors' offices and prisons in Kinshasa and the provinces.

Police reform efforts continued in the context of the Joint Discussion Group on Reform and Reorganization of the Congolese National Police (GMRRR), yielding the following preliminary results to date: (i) a preliminary draft framework law, which has been submitted to the Parliament; (ii) establishment of the Police Reform Monitoring Committee (CSRP); (iii) construction and equipping of an office building for the finance, budget, data processing, and human resources departments; and (iv) collection of data on police force staffing.

There were no significant developments in reform of the public administration in 2009 , but 3,741 civil service positions were eliminated nationwide through retirements. Modest progress was made in the decentralization process, where a progressive approach was ultimately adopted in regard to the principle of transferring 40 percent of national revenue and authority to the provinces. The transfer of powers is currently limited to the functions of the provincial governments and assemblies, and is supported by an institutional and human 
capacity strengthening program. The proposed framework law on the organization and operations of the Independent National Electoral Commission and the proposed annex to the electoral law establishing the distribution of seats were adopted.

In regard to economic governance, the government continued its program to modernize the public financial management system and financial administrations (establishment of provincial tax centers, conversion of the Customs and Excise Office (OFIDA) from government enterprise to government agency, creation of a unit within the tax administration (DGI) responsible for strategic sectors such as mining and telecommunications) and a legal and regulatory framework (proposed public finance act, proposed customs code, promulgation of a public procurement code). The expenditure cycle was extended to all expenditures, including emergency expenditures, to ensure transparency and traceability of government financial operations. The government adopted the Strategic Plan for Public Finance Reform (PSRFP) in March 2010.

In regard to public debt, the prime minister issued a regulatory text confirming the central role of the Directorate of Public Debt (DGDP), and an automated debt management system was installed.

Other significant actions. A new regulatory framework (National Statistics System, SSN) governing the production and use of statistics in the DRC was implemented in February 2010. Laws providing for the conversion of public enterprises and the government's withdrawal from commercial enterprises were implemented. The improved business climate, intended to improve the DRC's position in the Doing Business ranking, was central to the DRC's ratification of the OHADA Treaty. Also noteworthy was the creation of the Arbitration Center and National Mediation Center, which were provided with furniture, equipment, and information systems. Measures were implemented to simplify the creation of businesses. An AML/CFT and financial intelligence unit was established and began operations in October 2009.

To improve information on the employment situation in the DRC, two systems were implemented in February 2010, a registration system for individuals seeking employment and the Better Job Market Management through Effective Data Processing (PIEGMA) program.

Policies to support economic growth targeted agriculture, rural development, forests and the environment, mines and hydrocarbons, energy, and transportation infrastructures. The government adopted the harmonized agricultural and rural development strategy. It finalized a majority (30 of 42) of the implementing regulations under the 2009 forestry code. The first report under the Extractive Industries Transparency Initiative (ITIE), covering 2007, was produced in 2009 and is pending validation by an independent consultant. In regard to electricity production, an investment program funded the completion of a number of actions, including: (i) rehabilitation of Group 3 at the Inga 2 plant; (ii) acquisition of a Francis turbine runner at the Inga $2 \mathrm{~B}$ plant; (iii) completion of a rehabilitation study for the Zongo plant; (iv) installation of a $500 \mathrm{KVA}$ floating hydropower plant at Kananga; and (v) the provision of electric power to the city of Kindu.

In regard to transportation infrastructure, 22,900.60 kilometers of roads were completed, representing 113 percent of the target of 20,352.05 kilometers. The principal efforts involved modernization, rehabilitation, re-opening unpaved and rural roads, and large-scale maintenance projects. 
Significant progress was made in providing access to basic social services. In the education sector, the government's actions raised primary school enrollment from 64.1 percent in 2006 to 84.3 percent in 2008 , compared to a target of 80 percent projected in 2005 . Enormous challenges remain in regard to tuition-free, universal primary education and the achievement of Millennium Development Goals (MDGs). In the health sector, in addition to legal and regulatory measures, a number of national campaigns were conducted to combat disease (polio vaccination campaign, distribution of vitamin A and insecticide-treated mosquito nets, and vaccination of over 2 million infants under age one with financial support from the Global Alliance for Vaccines and Immunization (GAVI) and the United Nations Children's Fund, UNICEF). Additional actions reduced the under-five mortality rate from 172 to 148 per thousand over the reporting period; stabilized the neonatal mortality rate at roughly 38 per thousand; and increased BCG vaccination coverage. Finally, in regard to urban and rural drinking water supply, the rehabilitation of water collection plants in Lukaya and N'kjili and construction of the second water collection plant in Boma served to increase access to drinking water to approximately 27 percent.

In regard to the fight against HIV/AIDS, the strategy focused on preventing and stabilizing the transmission of HIV and sexually transmitted infections (STIs), accelerating treatment, improving the quality of life of persons living with HIV/AIDS, attenuating the socioeconomic impact of HIV/AIDS on the community, and strengthening coordination, monitoring, and evaluation capacities at all levels.

In the chapter on institutional arrangements for implementation, monitoring, and evaluation, the government recognizes weaknesses in strategic coordination at both central and provincial levels. In contrast, the implementation, monitoring, and evaluation activities of sector-level entities proceeded as planned, with support from technical and financial partners (TFPs). Beginning in mid-2009, the government began to address the situation by instituting weekly meetings to monitor progress toward reaching the completion point triggers under the HIPC Initiative.

To facilitate monitoring and evaluation of the Growth and Poverty Reduction Strategy, appropriate indicators were defined in the sectors identified as priorities in the first-generation GPRSP (education, health (including HIV/AIDS), agriculture, rural development, transportation infrastructure, and water and sanitation).

In conclusion, the Congolese government is pleased to have initiated an effort, with support from its technical and financial partners, to systematize its medium-term development planning, and to have resolutely done so in a very hostile domestic and external context. The results achieved are less important than the ultimate adherence to an approach that represents a clear break with ad hoc practices that marked years of poor governance.

The first-generation GPRSP would have produced more successful results were it not for the constraints faced over the entire implementation period, chief among which were:

- Limited internal resources to finance the GPRS, due to government revenue remaining low despite a relatively high rate of growth. This situation was exacerbated by a contraction of budgetary support following suspension of the program supported by the PRGF, which slowed the pace of reforms; 
- De-linking of the priority action plan (PAP), a key tool in implementing the GPRS, from the national budget, preventing it from being executed through the expenditure cycle. This situation is the result of lack of cohesion between the Budget Preparation and Monitoring Department, the Planning Department, and the sector ministries;

- Lack of communication between the government and the Bretton Woods institutions, which initiated the planning approach through the GPRSP, in regard to the use of a tool that was in an experimental phase in a post-conflict country. This state of affairs was not conducive to the understanding or full-fledged adoption of such an approach;

- Burdensome administrative procedures imposed on project execution by both TFPs and the government, impacting project cost evaluations in most cases;

- Social and political uncertainties created by the tensions of the 2006 elections, exacerbated by the climate of insecurity in the eastern part of the country, and their repercussions for public financial management and macroeconomic stability;

- The international food and financial crises followed by the collapse of commodities prices, which had devastating effects on economic activity and the management of public finances and currency.

Despite the constraints identified above, implementation of the GPRS produced encouraging results, as summarized below:

- Social sector indicators (health, HIV/AIDS, education, water and sanitation) improved. The greatest gains were made in the education sector, where the various indicators are on par with those of sub-Saharan African countries.

- The macroeconomic programs implemented during the period under review restored macroeconomic stability, as demonstrated by the conclusion of the IMF Extended Credit Facility in December 2009. However, the modest performance observed in regard to budgetary and monetary policies could have been strengthened if the reform program had not slowed, in which case the macroeconomic policies would have made a significant contribution toward reducing poverty.

- The emergency sector programs, projects, and actions in the areas of planning, security, transportation infrastructure, health, education, and water have restored peace and security and improved socioeconomic conditions, albeit slightly, for the Congolese people. They had a genuine impact on poverty reduction, primarily in terms of improved economic and social infrastructures and access to basic social services. The results described represent the execution of only half of the actions planned.

- The government recognizes that the strategic coordination of the GPRS was not commensurate with the importance of the issues at stake. It notes, however, that the weekly meetings instituted in the second half of 2009 to monitor progress on the HIPC Initiative completion point triggers signal a new direction in adapting government programs. In this regard, the government expects to intensify and rationalize its efforts in the context of the second-generation GPRSP. 


\section{RECOMMENDATIONS}

The recommendations draw on the lessons learned from implementation of the firstgeneration GPRSP. They shed light on the options that could emerge from the participatory consultations on the second-generation GPRSP. Certain GPRSP pillars, noted below form the basis of tomorrow's challenges:

a) Consolidating peace and security through continued actions to complete the pacification of national territory and end the humanitarian crisis, and by accelerating reform of the security sector;

b) Expanding the government's capacity to deliver quality social services by creating consensus as to the government's role and the need to better focus that role on its sovereign missions, and adapt the central and provincial administrations accordingly;

c) Promoting administrative and economic governance by continuing the decentralization process, adjusting it to reflect our available resources; through a relationship of accountability between government and the governed; through continued financial reforms and reforms of public enterprises; and through a genuine commitment to transparent mechanisms in managing natural resources (EITI++);

d) Strengthening the conditions of sustainable growth, through an improved business climate and implementation of a roadmap to raise the country's standing in the "Doing Business" category; intensified support for sectors with growth potential and the road, energy, and transportation infrastructures; and implementation of an aggressive commercial policy;

e) Giving serious consideration to the effects of climate change and issues pertaining to nature conservation; and

f) Mobilizing the private sector (including through public-private partnerships) to address the problems of financing development programs.

In reference to the important task of monitoring and evaluation, the government will face six major challenges: (i) reviewing and formalizing the monitoring-evaluation framework; (ii) securing the production of statistical data; (iii) renewing the operational and budgetary programming framework; (iv) implementing reporting tools: (v) developing a minimal framework for evaluating public policies; and (vi) increasing participation and communication. 


\section{INTRODUCTION}

The Government of the Democratic Republic of Congo (DRC) issues its second report on implementation of its Growth and Poverty Reduction Strategy Paper (GPRSP) for 2009 and its projections for 2010. This fulfills a twofold commitment made in adopting the GPRSP: first, to prepare an annual report on progress under the National Growth and Poverty Reduction Strategy (GPRS) in reference to the objectives of that strategy and the Millennium Development Goals (MDGs). In this regard, a midterm report on progress in implementing the GPRSP (for the period April 2007 to December 2008) was issued at end-2008; and second, to accomplish, through the progress report, one of the triggers required to reach the completion point under the Enhanced Initiative for Heavily Indebted Poor Countries (HIPC).

The DRC is determined to accomplish all of the HIPC completion point triggers in order to qualify for cancellation of substantial stocks of external debt under both the HIPC and the Multilateral Debt Reduction Initiative (MDRI).

In view of its participatory nature, the GPRSP is the frame of reference for the development of the DRC's economic and social development policies and programs. It establishes the approach and the clear, harmonized, shared objectives underlying the development of those policies and programs. It provides the framework for coordinating the efforts of the government and its social and external partners both in implementing the strategic pillars and in mobilizing the resources to finance implementation. The elected administration based its program and contract of governance (2007-11) on the strategic pillars of the GPRSP and secured its adoption by the Parliament in March 2007.

Preparation of the GPRSP occurred in two phases that required more than one year to complete due to practical difficulties, including limitations of the statistical apparatus and weakened human and institutional capacities in formulating development policies, the delayed consequence of years of political, economic, and social instability.

In the first phase, a participatory approach begun in 2001 led to the preparation of an interim version of the poverty reduction strategy paper (PRSP-I), in light of the difficult context marked by the initial steps away from armed conflict and government efforts to restore authority over the national territory and institute good governance. Through the successes of one year's implementation of the PRSP-I and six months' execution of one of its key components, the program supported by the Poverty Reduction and Growth Facility (PRGF), the DRC reached the decision point under the enhanced HIPC Initiative in July 2003 and was granted debt relief representing approximately $90 \%$ of the State's debt service, which was used to finance poverty-reduction expenditures.

In the second phase, a final version of the poverty reduction strategy (which had since become the Growth and Poverty Reduction Strategy Paper, GPRSP) was developed through a participatory approach involving all sectors of the population and the development partners. At the end of the process, the final version of the first-generation GPRSP was adopted by the transition government in July 2006, and subsequently endorsed by the government elected through free and democratic elections in March 2007. It was then presented to the World Bank Board of Directors and the IMF Executive Board, which adopted it in March and April, 2007, respectively. Following practical difficulties, the action plan for implementation of the first-generation GPRSP was finalized in July 2007. It should be noted, however, that the 
actions undertaken in 2006 with government and external financing had previously been finalized in the context of the Growth and Poverty Reduction Strategy (GPRS).

In July 2006, when the final version of the GPRSP was adopted by the transition government, the DRC was no longer under the formal program supported by the PRGF under which the macroeconomic stabilization efforts could be evaluated. This was an important element missing from both the second Enhanced HIPC completion point trigger and Pillar 2 of the GPRSP. An IMF staff monitoring program was instituted to restore the necessary conditions for conclusion of the new program under the PRGF. However, while awaiting renewal of that program, which would support the macroeconomic stabilization and growth program as one of the pillars of poverty reduction, and to allow sufficient time to prepare the secondgeneration GPRSP covering the period 2011 to 2015, the government decided in July 2009 to extend the term of the first-generation GPRSP to December 31, 2010.

After several renewals of the IMF staff monitored program on grounds of insufficient results, the government succeeded in December 2009 in demonstrating the outcomes required to conclude a new program under the new Extended Credit Facility, thereby filling the gap in the GPRS and kindling hopes for achieving the HIPC completion point by no later than June 2010 .

However, it is important to bear in mind the historical context in which the final GPRSP was prepared and implemented.

\section{Context surrounding the preparation and implementation of the final GPRSP}

The process of preparing the final version of the GPRSP, begun in 2003, and its implementation beginning in July 2007 took place in an extremely difficult context marked by:

- Widespread damage and destruction of economic and social infrastructures, posing a formidable obstacle to growth and development of the private sector,

- Uncertainties in regard to preparing and organizing the first genuinely free and democratic elections in a climate of heightened tension,

- Resumption of hostilities in the eastern part of the country, bringing grave humanitarian consequences,

- The global food and energy crises,

- The international financial crisis (the most serious since the Great Depression of 1929),

- The collapse of commodities prices and resultant contraction of government revenue,

- Lack of budgetary support since the 2006 suspension of the PRGF program, and

- Weak human and institutional capacities, particularly in the areas of statistics management, policy formulation, and the monitoring and evaluation of policy implementation. 
All of these factors adversely affected the management of public finances and currency and weakened the macroeconomic framework with volatile swings in the inflation and exchange rates and a sharp decline in economic activity. Moreover, they delayed the program of reforms, leading to disappointing results under both the IMF staff monitoring program and sector projects and programs. In particular, public financial management continued to contend with an obsolete legal framework, opaque budgetary procedures, ineffective control mechanisms, and lax budgetary schedule.

The environment, then, was hardly conducive to the DRC's fully embracing and embarking upon an unprecedented task of the scope, complexity, and technical rigor involved in the preparation and implementation of the GPRSP.

\section{Report methodology}

The report on implementation of GPRSP was prepared during March 2010 through a participatory approach that involved various working groups conducting sector reviews in addition to an overall review. These working groups comprised close to 500 participants, including representatives of the Parliament, the Office of the President, the Prime Minister's office, the public administrations, social society organizations, the technical and financial partners (TFPs), the private sector, and the provincial governments.

The sectors identified in the GPRSP as priorities (health, education, and water and sanitation) and as having growth potential (agriculture and rural development) were reviewed separately. Civil society organizations also formed working groups to compile their assessments with respect to implementation of the GPRSP. The results of these evaluations were presented at the general review of the GPRSP on March 8 and 9, 2010.

The evaluation of the GPRS implementation basically addresses actions undertaken both under the priority action plan (PAP) and otherwise during 2009. Note that this report does not address the incidence of poverty. Given that no new 1-2-3 survey was conducted during implementation of the GPRS, it was not possible to update the poverty profile and identify trends. The government expects to launch the survey, with support from the TFPs, no later than October 2010, which will enable it to gather the information required to analyze poverty.

In addition, the DRC's development partners conducted a midterm assessment of the Country Assistance Framework. The conclusions of their evaluation were incorporated into this report.

\section{Framework}

The introduction to this report reviews the purpose of the report and the steps taken in formulating the GPRSP, and describes the context surrounding the preparation of the GPRSP and the methodology used to review the implementation of the GPRS. The remaining three chapters of the document address the principal pillars of the GPRS, macroeconomic policies, sector policies, and the monitoring and evaluation mechanism.

The first chapter reviews macroeconomic performance between January 2009 and March 2010, which demonstrated that domestic growth and price stability, brought about by rational, prudent budgetary and monetary policies, influenced poverty. This section also reviews sector budget allocations to highlight the quality of public expenditure, particularly in respect of the GPRS priorities. 
The second chapter reviews sector policy results and trends in terms of improved social conditions for citizens.

The third chapter addresses the operation of the GPRS coordination structure and the monitoring and evaluation mechanisms.

The conclusion reviews the lessons learned from implementation of the GPRS and recommendations in terms of future challenges. 


\section{Chapter 1: ANALYSIS OF MACROECONOMIC PERFORMANCE AND EXPENDITURE}

\section{Introduction}

One of the pillars of the war on poverty identified in the participatory consultations was the consolidation of macroeconomic stability and growth. It is important, then, to evaluate the results of the economic and financial policies implemented in the context of the GPRS. To that end, two macroeconomic stabilization programs were executed.

The first program covered the period from 2006 to November 2009 (independent IMF staff monitoring program), and was instituted in April 2006 following suspension of the PRGF program. The second program, supported by the Extended Credit Facility, was concluded in December 2009. Sector reforms were implemented in support of that program. The evaluation focuses on the results of macroeconomic policies conducted in 2009 and early 2010. The first part of this chapter examines macroeconomic performance, and the second reviews budget allocations by category and by GPRSP pillar and component.

\subsection{Recent developments in the Congolese economy}

The effects of the financial crisis continued to weigh heavily on the Congolese economy during 2009. The decline of mining exports, primarily in the first half, and their effects on the rest of the economy considerably dampened economic activity.

\subsubsection{Economic activity and prices}

In 2009, economic growth slowed in comparison with the previous year (6 percent) but was slightly above the established target. According to central bank (BCC) estimates based on end-December 2009 business surveys, real GDP growth was 2.8 percent compared to an objective of 2.7 percent, the result of a third-quarter recovery in the mining sector and spillover effects on the tertiary sector.

Inflation reached 53.4 percent, corresponding to an annual average of 46.1 percent, compared to a target of 48.7 percent. The indicative US dollar-Congolese franc exchange rate was 902.7 at end-December, representing a depreciation of 29.2 percent compared to the same period of 2008 .

\subsubsection{Public sector}

The overall public sector financial situation improved from 2008 to 2009 despite the fact that not all external resources programmed were disbursed. Domestic revenue excluding [concession-related] bonuses fell, reflecting a drop in customs and petroleum receipts as a result of the international financial crisis. The government remained determined to control spending to maintain macroeconomic stability, despite increased security expenditures due to the worsened security situation in the eastern provinces and recently in the west. As a result, the domestic budget deficit (cash basis) was -3.1 percent of GDP, compared to a projected surplus of 3.3 percent. 


\subsubsection{External sector}

The Congolese economy withstood the effects of the international financial crisis in 2009, with a better overall external position in comparison to the previous year. The current account deficit, which increased sharply in 2008 to nearly 15.9 percent of GDP due to increased imports and the drop in prices of key commodity exports (particularly copper and cobalt during the second half of 2009), declined to about 12.9 percent of GDP in 2009. This reflects a substantial increase in emergency international aid, which enabled Congolese authorities to limit the impact of the financial crisis on the economy. Disbursement of the first tranche of funds under the Sino-Congolese arrangement also helped cushion the exogenous shock.

These positive developments and increased balance-of-payment support from the IMF, especially the general and special allocations of special drawing rights (SDR) totaling SDR 424.5 million (approximately US $\$ 662.3$ million) and disbursements under the Exogenous Shocks Facility and Extended Credit Facility, significantly increased international reserves in 2009, despite low levels observed in first quarter 2009. International reserves, which stood at US\$27.16 million on March 11, increased to US\$999.4 million, representing 9.1 weeks of nonaid imports.

\subsubsection{Monetary sector}

The money supply expanded, due essentially to external contributions despite improvement of public finances. Of the 50.5 percent increase in comparison to the previous year, 66.1 percent was contributed by net domestic assets, despite a 26.3 percent decline in net credit to the government. The share of internal assets contributing to growth was also significant, at 33.4 percent including external financing disbursed in 2009, and allowed the BCC to execute currency market interventions totaling US $\$ 124$ million to control volatility. In addition, under its restrictive policy to limit deviations of inflation from the targeted 31.2 percent, the BCC modified the official rate three times in 2009 (in January and October) raising it from 40 percent at end-2008 to 55 percent, 65 percent, and 70 percent, and increase the required reserve ratio from 5 to 7 percent between January 2008 and October 2009.

\subsubsection{Economic situation at end-March 2010}

Macroeconomic developments at end-March 2010 were encouraging. Year-to-year inflation declined from close to 47.6 percent in February to 34.3 percent in March, and annualized inflation stood at 19.6 percent in March compared to 50.9 percent in February and an annual target of 15 percent. The Congolese franc (CDF) appreciated 1.6 percent against the US dollar, from CDF 921.1 at end-February to 906.3 at end-March. The lull in currency and goods and services markets allowed management of the treasury plan on a cash basis, resulting in a budget surplus at end-March 2010. Amid the relative stability, the BCC lowered the base rate on March 23 to 52 percent from 70 percent (in February) to reduce the positive spread. 
Figure 1. Democratic Republic of the Congo: Economic Developments, 2002-08
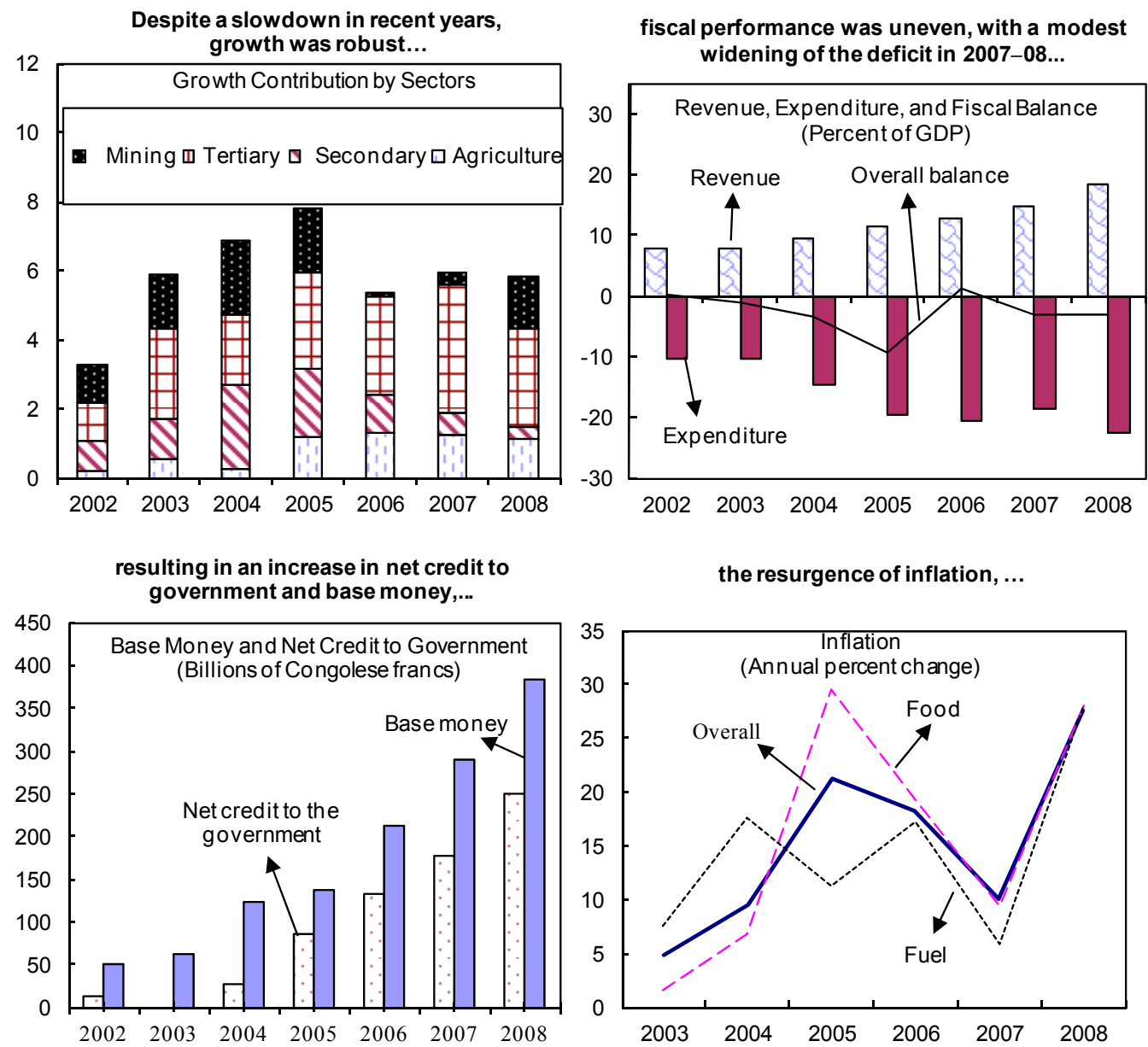

a widening of the external current account deficit, ...

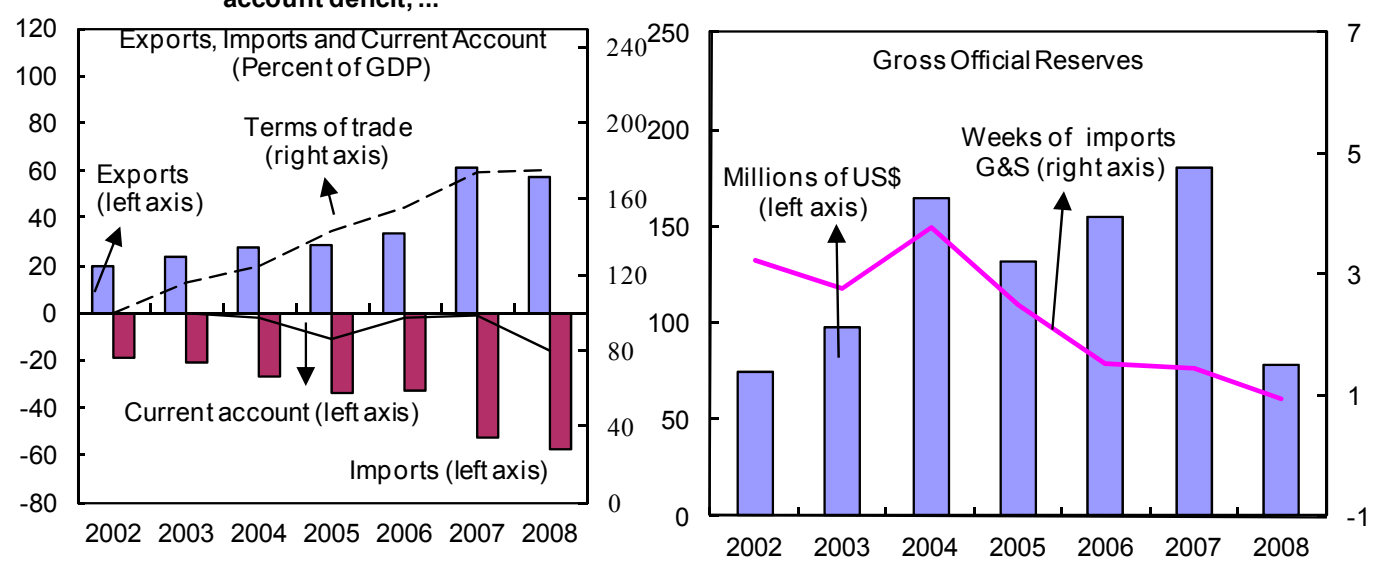

Sources: Congolese authorities; and IMF staff estimates. 


\subsection{Expenditure analysis}

\subsubsection{Analysis of budget expenditure by category}

Overall, the government budget execution rate was $63.2 \%$. This under-execution represents an increase of 13 percent in comparison with the previous year. Compared to GDP, however, it represents a decrease of roughly 4 percentage points, largely explained by the decline in revenue produced by the international financial crisis, described in the above paragraph on macroeconomic performance, particularly in the public sector. The under-execution conceals the overrun in the "defense" function representing 0.6 percent of GDP, which was more than offset by under-consumption in all other functions except "religion, culture, sports, and recreation," for which the impact of the global overrun was deemed minor. Note that the "Central public administration" and "national defense" functions alone absorb more than one-half of credit, compared to the two-fifths provided in the budget.

Figure 1. DRC - Budget composition by function, 2006-09

(As \% of GDP)

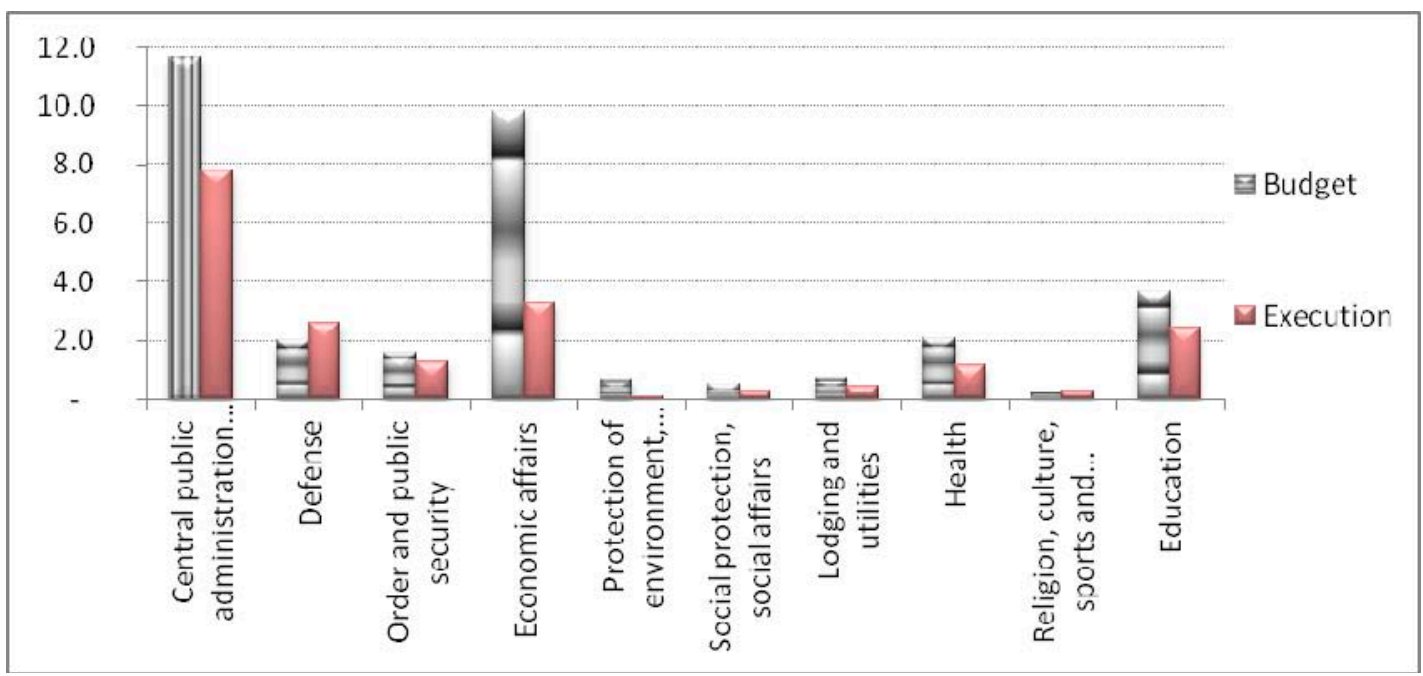

Personnel expense in proportion to total primary expenditure decreased from 35.2 percent to 32.9 percent between 2008 and 2009. This demonstrates the government's close attention to this item in economic programming, given that it can be a potential source of inflationary pressures in a context of limited capacity to mobilize domestic resources.

Current non-salary primary expenditure remained the largest item of public expenditure. This was due primarily to government transfers and interventions, which increased from 22.7 percent to 33.0 percent of primary expenditure between 2008 and 2009 following decentralization and transfers to revenue-collecting agencies. In contrast, the proportion of spending for goods and services declined sharply over the period, from 6.6 percent of primary expenditure in 2008 to 3.9 percent in 2009, well below the level needed to support effective functioning of public administrations. 
Figure 2. DRC - Composition of primary expenditure by category, 2009

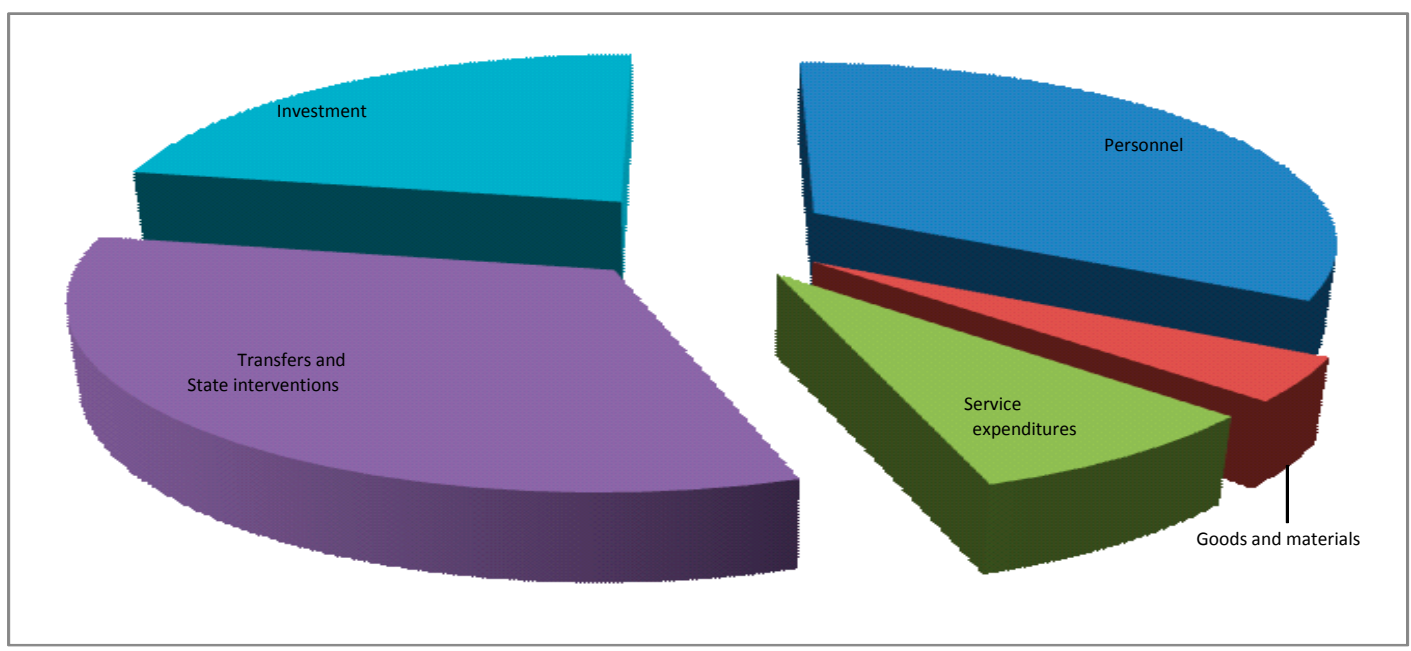

Public investment expenditure declined from 4.7 percent of GDP in 2008 to 4.3 percent in 2009. The overall share of these items in proportion to total primary expenditure remained stable at roughly 21 percent between 2008 and 2009. However, this ratio is clearly inadequate to meet the reconstruction objectives fixed by the government. At the same time, much of this investment is financed by external resources, which are not fully captured in the national budget. In other words, the above analysis underestimates public investment.

In 2009, repayment of principal represented 4.7 percent of total public expenditure, compared to 3.6 percent in 2008. Interest payments on the debt represented 3.1 percent of public expenditure in 2009, compared to 3.8 percent in 2008 and 9.8 percent in 2004 . Total debtrelated public expenditure represented 7.9 percent of GDP in 2009 compared to 7.4 percent in 2008. Public debt remains a significant burden for the government, representing 7 percent of total public expenditure in 2009, more than all health-related spending for the same year. It is essential, then, that the DRC achieve the HIPC Initiative completion point in order to free up additional fiscal headroom needed for a more active development policy.

\subsubsection{Public expenditure in relation to GPRSP priorities ${ }^{1}$}

The analysis of expenditure by pillar following Figure 4 below highlights the importance of the strategic pillar "Promoting good governance and peace." Spending for this pillar represented roughly 60 percent of primary expenditure in 2009. This spending was bloated by increasing sovereignty and security expenditure relating to the conflict in eastern Congo, and recently in the West, and above all by transfers to the provinces and revenue-collecting

\footnotetext{
${ }^{1}$ The analysis of budget allocations to the various sectors of the national poverty reduction strategy required the preparation of a correspondence table to convert functional budget classifications to the thematic classifications used in the GPRSP. The table shows primary public expenditure for the period broken down by strategy pillar and sector. Certain approximations were unavoidable in re-classifying the functional categories by pillars and sectors. Also, since it was not possible to segregate expenditures for Pillar 4, "Combat HIV/AIDS," from Pillar 5, "Local initiatives," they are not presented in the analysis but are included in Pillar 2, "Support sectors with growth potential" and Pillar 3, "Promoting access to basic social services."
} 
agencies. The predominance of this spending reflects the post-conflict context and the need to strengthen institutions and administrations and consolidate peace.

Figure 3. Budget execution by strategic pillar, 2006-09 (As \% of primary expenditure)

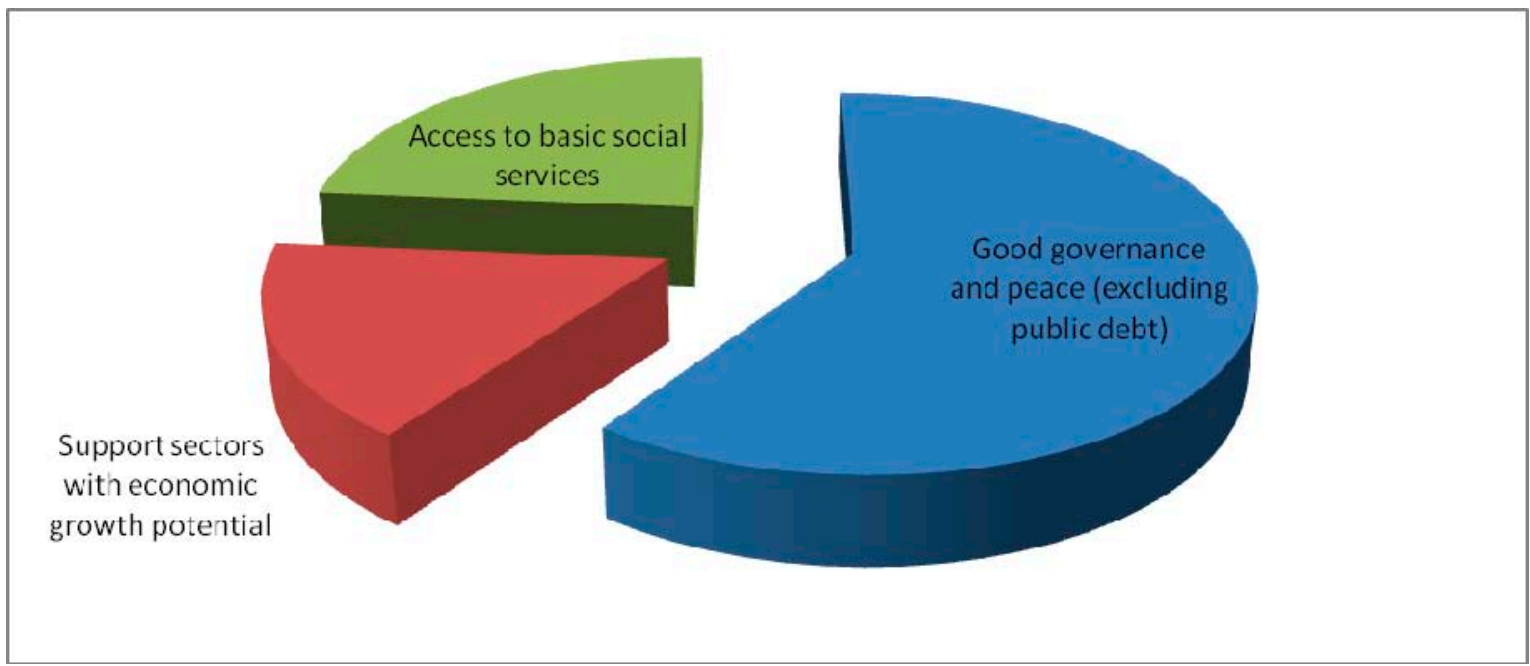

The second most important pillar is Pillar 3, "Promote access to basic social services," which declined slightly in proportion to total primary expenditure, from 24.9 percent in 2008 to 23.6 percent in 2009. Pillar 2, "Supporting sectors with growth potential," increased from 16.2 percent in 2008 to 16.5 percent in 2009. 
Figure 4. Composition of Budget Expenditures by strategic Pillar, 2009

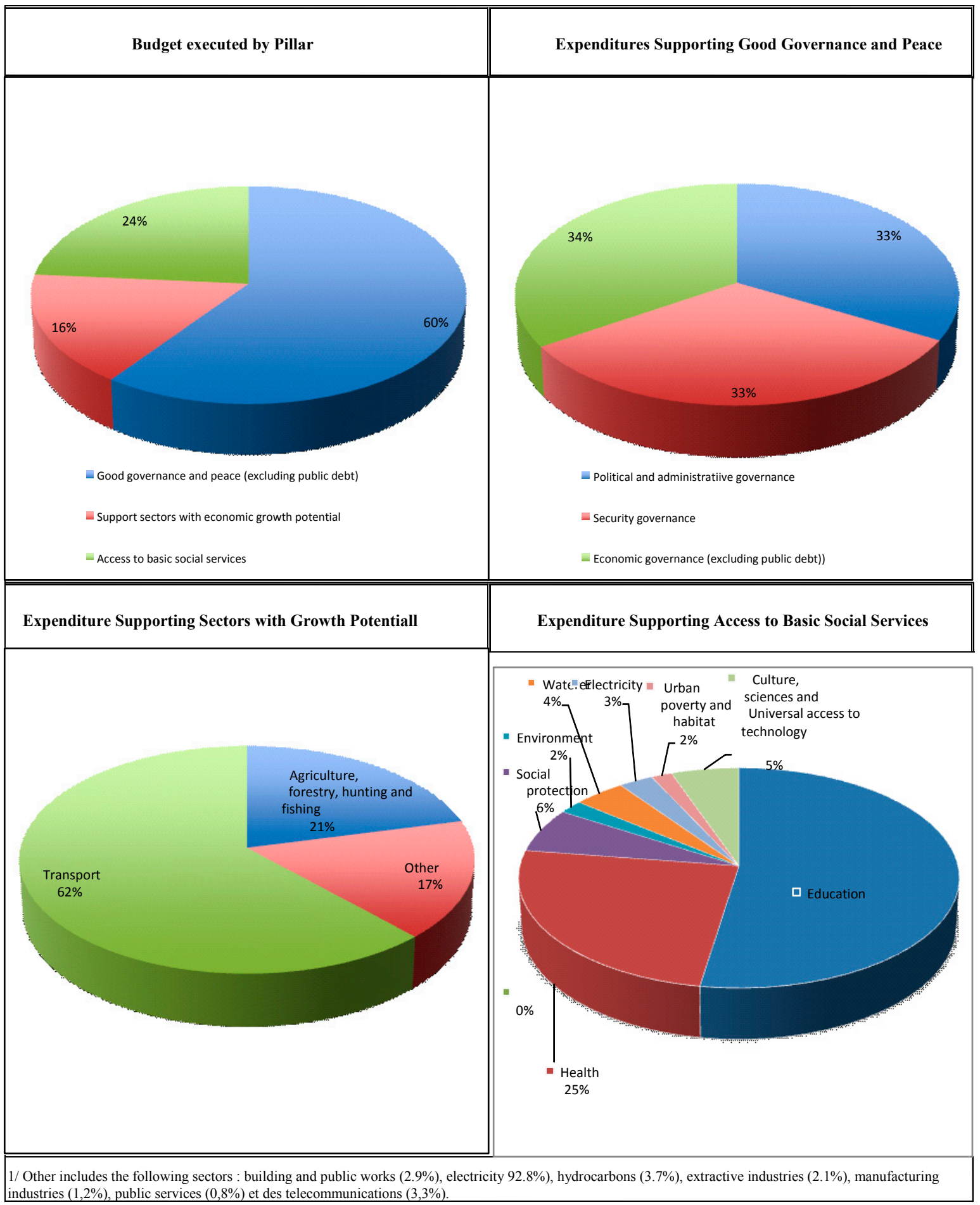

\section{CInternational Monetary Fund. Not for Redistribution}


The above graphs confirm the substantial expenditures devoted to political, security, and administrative governance, totaling roughly two-thirds of primary expenditure for all of 2009. This increase could be explained by significant over-execution in 2009 , close to 180 percent, relating to emergency security measures. Spending on economic governance (excluding debt) is also substantial in proportion to total primary expenditure following an execution rate of only 191.7 percent.

The sector-specific analyses clearly show that transportation, particularly road infrastructure, accounts for over one-half of spending for this pillar. However, the execution rate for this sector appears particularly low, with less than 30 percent of Pillar 2 expenditure executed in 2009. The next largest sector for this pillar is agriculture, although it represents only onethird the amount of transportation spending. Finally, the extractive industries, manufacturing, and building and public works (excluding roads) represent a small proportion of Pillar 2 expenditure.

Social expenditure (Pillar 3) declined relative to GDP, from 5.8 percent of GDP in 2008 to 4.6 percent of GDP in 2009, and its relative share in proportion to total primary expenditure declined over 2008-09. The largest sector of the pillar in terms of expenditure was education, which declined in proportion to total primary expenditure from 13.7 percent in 2008 to 12.4 percent in 2009. Despite a high execution rate, close to 74 percent, spending in this sector relative to GDP declined from 3.2 percent of GDP in 2008 to 2.4 percent in 2009. The second-largest social sector, health, was more stable relative to total primary expenditure, increasing 0.2 percentage points between 2008 and 2009. The execution rate in this sector was relatively weak, at 61.6 percent in 2009. The share of spending on other social sectors (social protection, environment, urban poverty and housing, and culture) was relatively marginal in terms of both GDP and total primary expenditure, remaining flat or declining slightly over the period. Given the crisis context, execution rates for these sectors varied widely and were generally low, particularly for social protection, the environment, and water.

\subsection{Medium-term macroeconomic prospects}

The government recognizes that continued, sustainable growth in a stable macroeconomic climate is essential to reducing poverty. The medium-term macroeconomic objectives remain in line with those agreed in the recent PRGF arrangement. Stated in quantitative terms, the objectives are: (i) reduce year-to-year inflation to 9 percent by end-2012; (ii) increase international reserves to 10 weeks of nonaid imports by end-2012; and (iii) achieve real GDP growth in the range of 6 percent per annum. To achieve these objectives, the government intends to reduce the domestic balance and refrain from central bank financing while increasing fiscal headroom to provide essential public goods. It will achieve this by implementing reforms to increase revenue and rationalizing and prioritizing public expenditure. Progress in the consolidation effort will strengthen the central bank's capacity to meet inflation objectives. The government will continue economic reforms to promote the private sector, the driver of the Congolese economy. These policy options were among the principal recommendations of the 2007 Article IV consultations. The government will also adjust the composition of expenditure to better serve the objective of reducing poverty. 


\section{Chapter 2. ACTIONS IMPLEMENTED}

\section{Introduction}

We review below the record of reforms and projects implemented in an attempt to explain the decline of property. We should note, however, that it was not possible to undertake the task of establishing cause-and-effect relationships during implementation of the GPRS, for the following reasons:

- The sector ministries included a number of actions in the priority action plan (PAP) despite insufficient visibility in terms of feasibility studies and identification of confirmed sources of financing. Several actions reflected intentions expressed by partners or ministers for which the costs and execution time tables had not been determined;

- Certain TFPs preferred to execute the projects or activities they financed directly, with support from sector ministries or NGOs;

- The PAP and the budget were not reconciled in regard to executing the actions identified in the PAP. However, in order to provide a comprehensive view of the efforts undertaken to achieve the GPRS objectives, the report includes both PAP activities and non-PAP activities aligned with GPRS priorities.

\subsection{Promoting good governance and consolidating peace through strengthened institutions}

\subsubsection{Security and judicial governance}

\section{a. Security}

The government set itself the objective of consolidating national reunification and territorial administration; accelerating integration of the army, police, and security services; and ensuring the return and reintegration of displaced persons within and outside the country. Actions were taken to reestablish peace and the government's authority in the eastern and western provinces. The Goma peace accord (Amani Programme) signed on January 23, 2008 resulted in the cessation of hostilities with armed groups, assimilation of militiamen into the regular forces (brassage), and the gradual disengagement of various armed groups.

The government launched the joint Umoja Wetu (Our Unity) operation with Rwanda, which put down the CNDP rebellion and ended hostilities in the eastern part of the country. The Congolese army, with support from the UN peacekeeping mission (MONUC), initiated the Kimia I and II peace operations targeting the remaining pockets of armed groups. The effort continues today with Amani Leo. The assimilation, disarmament, demobilization, and integration of former CNDP combatants and other armed groups (Mayi Mayi, PARECO, etc.) continued under several government programs, including the program supported by several partners to pay ex-combatants US\$100 to surrender their arms. In parallel, several units were established and equipped at the Kisangani, Kamina, and Ruberizi assimilation centers. 


\section{b. The judicial system}

The government's policies in the administration of justice are based on reform, improving access to justice, promoting and protecting human rights, modernizing the legal framework, combating corruption and impunity, and strengthening human and institutional capacities.

The following actions were implemented or are in progress: (i) an organizational and institutional audit of the Ministry of Justice, resulting in modification of the ministry's structural framework; (ii) the drafting of the Constitutional Court act, which is pending adoption by the Parliament; (iii) construction in progress on a new courthouse in the context of the Governance Support Project (PAG); (iv) the organization of awareness-raising campaigns for hundreds of citizens and users of public services in the provinces of Kinshasa, South Kivu, Maniema, and Equateur; and (v) restructuring of the Conseil Supérieur de la Magistrature, the administrative body of the judicial branch.

\section{Box 3. Strengthened judicial system infrastructures}

To promote the sound administration of justice, infrastructures supporting the courts, prosecutors' offices, and penitentiary institutions were constructed or rehabilitated in the provinces of Kinshasa (the the Ndolo military prison and the commercial courts of Kinshasa/Gombe and Kinshasa Matete), Bas-Congo, Bandundu (the Prison du Cinquantenaire), North Kivu (the Beni magistrate's court and Goma military courthouse), South Kivu (Kalehe and Uvira magistrate's courts, the Uvira and Bukavu military courthouses), West Kasai, East Kasai, Orientale (the Aru, Mombasa, and Mahagi magistrate's courts), and Katanga (the Katanga commercial court). A number of them were equipped for operation.

\section{c. Army}

In February 2008, a roundtable on security reform was held in Kinshasa and attended by a number of bilateral partners. The roundtable produced the following recommendations:

- In the context of a new master plan, implementation of a Congolese coordinating unit to review contributions to army deterrence programs, MONUC retraining efforts, and the formation and equipping of general-purpose combat units;

- Rigorous control of personnel through biometric identification;

- Establishment of a rapid-response force capable of relieving the MONUC, securing the eastern part of the country, and performing the constitutional responsibilities incumbent on the army (implemented with financing from the Netherlands). This effort was undertaken in 2008, implementing the second phase of the strategic plan for reform of the army.

Regarding the military component of the master plan, the partners agreed to support the DRC in implementing a human resources management tool.

\section{d. Police}

With support from the TFPs, the Government continued the work of modernizing the Congolese National Police undertaken by the Joint Discussion Group on Reform and Reorganization of the Congolese National Police (GMRRR). These reforms resulted in: (i) the preliminary draft of a framework law, which has been submitted to the Parliament for adoption, and establishment of the Police Reform Monitoring Committee (CSRP); (ii) 
construction and equipping of an office building for the finance, budget, data processing, and human resources departments; and (iii) collection of police force staffing data.

\section{e. Sexual violence}

The government is committed to eradicating sexual violence. The following actions were implemented: validation of the communication and prevention strategy document on sexual violence, meetings and advocacy actions among stakeholders in the fight against sexual violence, implementation of a sexual violence hotline, informational activities in regard to the law on sexual violence, and comprehensive care for victims of sexual violence.

\subsubsection{Political and administrative governance}

\section{a. Public administration}

The government's objective in this sector is to reorganize and modernize public services at all levels of the public administration by strengthening the institutional framework and human capacities and controlling staffing levels in the central and provincial governments. A draft legal framework for the public administration was prepared in 2009 and is awaiting adoption by the Council of Ministers. Also, in the interest of controlling civil service staffing, actions were implemented to compile a comprehensive register and ensure the conformity of employees and officials. Also, to reduce the average age and increase the efficiency of government agencies, the government processed the retirements of 3,741 government employees and officials nationwide during the period 2009-2010.

\section{b. Local governance}

The government's decentralization policy aims to: (i) allow citizens to participate in the public sphere and formulate development policies in the areas that concern them; (ii) refocus the central government mission on establishing major policy objectives; (iii) promote rapprochement between government and the governed; (iv) simplify administrative procedures and promote a participatory, inclusive culture to strengthen the development of decentralized administrative entities.

To further the process of decentralization, a single, consensus-based frame of reference, the Strategic Decentralization Implementation Framework (CSMOD), was established in June 2009. A gradual approach was adopted with respect to the principle of transferring 40 percent of national revenue and authority to the provinces. In particular regard to the transfer of authority, the functional institutions at this time are the provincial governments and assemblies.

With support from the TFPs, the government also took action to promote local leadership, accountability and skills in basic tools in the central and provincial administrations and decentralized agencies. The program to train provincial deputies, decentralized agency personnel, and civil society stakeholders in provincial and local planning processes continued in the provinces of Bandundu, Katanga, Maniema, and South Kivu. The government also conducted missions through the planning and budget ministries in 2009 to support the development of planning and programming tools (the PAP, macroeconomic framework, and 
medium-term sector expenditure frameworks) in all provinces, in cooperation with the World Bank and the United Nations Development Program (UNDP).

\section{c. Elections}

The proposed law establishing the organization and operations of the Independent National Electoral Commission and the proposed annexed to the electoral law establishing the distribution of seats were adopted.

\subsubsection{Economic governance}

\section{a. Tax and customs revenue policies}

Tax policy and tax and customs administrations. The government is committed to implementing an efficient, modern fiscal and customs policy. The proposed VAT law was approved by the government and submitted to the Parliament for adoption. At the same time, the government continued establishing tax centers in certain provinces. To improve security in the collection of customs revenue, the Customs and Excise Directorate (DGDA) improved information systems based on Asycuda++ by completing the migration from Asycuda 2.7 to Asycuda++ at the Eastern Kinshasa and Kinshasa airport offices. The results of the first signal test were conclusive. The Asycuda++ software was presented to all service providers at the inspection certification offices (BIVAC) on Friday, January 22, 2010, and the DGDA information center was officially launched on Tuesday, January 27,2010 . In addition, to strengthen the supervision and implementation of reforms, the Customs and Excise Office (OFIDA) was elevated by Executive Order (Décret) 09/43 of December 3, 2009 to an executive agency under the Ministry of Finance to become the DGDA. The proposed new customs code was also approved by the government on January 8, 2010 and submitted to the Parliament for review and adoption.

Taxation of the mining sector and streamlining of exemptions. The government intends to increase revenue by increasing mining sector contributions to domestic revenue and rationalizing exemptions. Strategic, specialized sector units, including a mining tax unit, were established within the DGDA Large Enterprise Department (DGE) on April 27, 2009. In regard to rationalizing exemptions, the government adopted the report of the commission charged with evaluating the tax incentives and exemptions provided under the Mining Code, the Investment Code and special agreements in March 2010. The report includes an action plan for implementing its recommendations.

\section{b. Public financial management}

Modernization of the public financial management system. The government recognizes the need to modernize public finances to ensure effective budget preparation and execution. To this end, a Strategic Plan for Public Finance Reform (PSRFP) was adopted by the government in March 2010. The plan includes three components: (i) the strategy framework document, which presents the government's strategic options in this area and serves as a convenient reference for the various stakeholders in order to better coordinate actions; (ii) a three-year action plan for reforms to be implemented in five areas: (a) budget planning and preparation, (b) the fiscal system, (c) expenditure management, (d) accounting and cash management, and (e) the system of controls, and (iii) indicative cost tables. The government 
strengthened the mechanism for coordinating and implementing public finance reforms by establishing the Steering Committee on Public Finance Reform (COREF) in August 2009.

Legal framework governing public financial management. The government adopted a proposed law on public finance in March 2010. The proposed public procurement code was adopted by the Parliament in April 2010 and is pending official publication; the implementing regulations have also been prepared and will be promulgated following publication of the code. Efforts are under way to revise the general public accounting regulations. The government has also begun to rationalize revenue nomenclature used by the Directorate of Administrative and State Revenue (DGRAD), anticipating forthcoming efforts to prepare and adopt a proposed law on revenue nomenclature recognized by the provinces in accordance with constitutional provisions.

Budgetary transparency, traceability of State financial operations, and control of wages and salaries. In February 2010, the manual on the budget process and public expenditure cycle was revised. The revision reflects the integration of emergency spending procedures in the expenditure cycle. For the provinces, the March 2010 validation of the provincial expenditure cycle manual established the standard for executing public expenditure. In regard to the accounting system, the Treasury Management and Payment Authorization Office (DTO) produced account balances through end-December 2009. The government improved the reliability of the Simplified Transitional Procedure implemented in July 2007. A roadmap was adopted to extend this automated procedure to all payroll items in all the provinces. Budget monitoring reports were produced on a regular basis, despite certain weaknesses in terms of reliability and completeness of information. The government is endeavoring to correct malfunctions that persist in the budget monitoring system. Similarly, the expenditure cycle was strengthened through the inclusion of payroll and public debt expenditure. In parallel, the government undertook actions to modernize the cycle by acquiring new hardware and more robust software. The government also intends to strengthen public financial control through the support of oversight entities. In this regard, plans are under way to establish a financial inspector's office and court of accounts.

\section{c. Public debt management}

The government is committed to pursuing a prudent borrowing policy to ensure that public debt is sustainable. Government actions focused on strengthening institutional and human capacities to manage debt and settling domestic debt. In this context, Executive Order 08/04 strengthening the central role of the Directorate of Public Debt (DGDP, the former Public Debt Management Office, OGEDEP) in managing public debt, was signed on February 28, 2008, and implementation of the related action plan adopted in May 2008 began with the launch of data collection efforts and informational activities. The DGDP also collected data on public debt in Kinshasa and the provinces for the purpose of centralization.

In October 9, the government amended the cooperation agreement with a consortium of Chinese enterprises to ensure that its terms were compatible with the imperatives of debt sustainability. The accord provided sovereign guaranteed financing for project infrastructures totaling US\$3 billion. The debt contracted to finance the project will be repaid from profits of the joint venture formed by Congolese public enterprise GECAMINES and the Chinese enterprises. The sovereign guarantee would be executed only if the joint venture fails to repay the full amount of the debt within the first 25 years of the joint venture, or 2034. In this context, the government believes that the cooperative agreement contributes to the 
objective of debt sustainability and incorporates the level of concessionality required to ensure debt sustainability.

The government is normalizing relationships with all its creditors. On February 25, 2010, the government concluded the eleventh rescheduling arrangements with Paris Club creditors following approval of the new PRGF arrangement on December 11, 2009. Once the HIPC Initiative completion point is reached, the authorities will open bilateral negotiations with each of the Paris Club, non-Paris Club and Kinshasa Club creditors. The Paris Club secretariat will provide the DRC with an ex ante valuation of the amount owed to each creditor prior to the conclusion of bilateral negotiations. In addition, the World Bank has provided a grant to the DRC to support repayment of its London Club commercial debt.

\section{d. Restructuring the national statistics apparatus}

The government identified statistics as a priority area of strengthening to improve policy formulation and monitoring. To this end, the government strengthened the capacity of the National Institute of Statistics (INS) by converting it to a public institution with separate legal status. Currently, the production and use of statistics in the DRC are governed by Executive Order 10/05 of February 11, 2010 on the National Statistics System (SSN). In addition, the INS has made its DEVINFO human development database available online through its website.

\section{e. Promoting the private sector}

Actions to promote the public sector proceeded in [four] directions, reforming public enterprises, reviving the business climate, employment, and reforming the financial system.

\section{- Reform of public enterprises}

The actions taken in 2009 consisted of: (i) implementation of four laws reforming public enterprises $^{2}$ enacted in July 2008; (ii) the implementation of management contracts to stabilize the technical and financial activities of the National Transportation Office (ONATRA), the Congolese national railroad company (SNCC), and the National Aviation Administration (RVA); and (iii) transfer of customs-related activities from the Ministry of Trade Inspection Office (Office Congolais de Contrôle) to OFIDA (now the DGDA).

\section{- Business climate}

Actions in regard to the business climate included establishing commercial courts in Kinshasa and Lubumbashi, ratifying the OHADA Treaty, and equipping the national arbitration center and national mediation center with computer hardware and furnishings. Measures were also implemented to streamline the process of creating enterprises.

To protect the financial sector from instability in regard to funds of doubtful origin, a financial reporting and anti-money laundering and terrorism financing unit was created and put in operation in October 2009.

\footnotetext{
2 The laws concerned the conversion of public enterprises, the organization and operation of public institutions, privatization of government-owned enterprises, and the organization and management of public enterprises.
} 


\section{- Employment}

The 2009-2010 PAP identified two programs to stimulate employment: (i) support for formulation of the national policy on employment and professional training and jobs for youths; and (ii) strengthened institutional capacities and human resources development. In regard to the first program, a proposed national policy on employment and professional training was drawn up in 2009 with support from the International Labor Organization. The document was validated in March 2010 by committees formed in connection with the thematic group.

In regard to strengthening the capacities of ministry and legislative secretariats and the Office of the Labor Inspector (IGT), an information requirements questionnaire was drawn up and administered in February 2010. In order to improve the quality of employment-related information in the DRC, the National Employment Office (ONEM) implemented a registration system for the jobless. The database includes 60,000 individuals seeking employment at this date. In March 2010, ONEM began issuing biometric cards to registrants. In the same vein, the Better Job Market Management through Effective Data Processing (PIEGMA) program was implemented in February 2010, and the Employment and Professional Training Observatory was also created.

\section{Box 4. The PIEGMA Program}

The Better Job Market Management through Effective Data Processing (PIEGMA) program is charged with: (i) producing indicators on job opportunities and training by implementing a mechanism to monitor graduates and other categories of job seekers in the labor market; (ii) publishing key market indicators; (iii) periodically conducting surveys by compiling censuses, lists of occupations and similar tools to determine labor needs by qualification in the national economy; and (iv) preparing job descriptions that specify the required skills, conditions of access, and other terms relevant to each position to provide the job market with adequate information on job opportunities.

\section{- Financial system reform}

To improve access to financing and strengthen the financial sector's role in reviving the national economy, the standards and criteria for supervision of commercial banks were strengthened. In July 2009, the BCC published statements of financial affairs for the two public banks in liquidation (Nouvelle Banque de Kinshasa and Banque de Crédit Agricole). In 2008 and 2009, the government approved charters of private banks and micro-finance institutions, thereby increasing the number of banks in the country and the level of financial intermediation. In June 2009, a strategy was adopted to reorganize the BCC, streamline its operations, and reduce its operating deficit. Actions to modernize the $\mathrm{BCC}$ and introduced new liquidity management instruments are continuing.

\subsection{Policies supporting economic growth}

\subsubsection{Agriculture and rural development}

The government's objective in this sector is to restore a level of agricultural production to meet the nutritional needs of the entire population, and restore the bases of social cohesion so as to ensure sustainable peace and stability in the country. To this end, the Government undertook institutional reforms of the Ministry of Agriculture and conducted a preliminary institutional assessment; and developed a proposal for restructuring the Ministry of Rural 
Development; and adopted a harmonized strategy for the agriculture and rural development sector.

To support agricultural production, ${ }^{3}$ improved seeds were distributed and rural producers were provided with training; these actions served to improve crop production and stabilize prices. The physical achievements during implementation of the GPRSP include: (i) 10,317 kilometers of rural roads rehabilitated and 7,500 kilometers of rural roads being maintained with financing from the Kingdom of Belgium; (ii) 120 kilometers of rivers and streams improved; (iii) buoys installed in 40 kilometers of waterways with government financing; (iv) three National Seed Service (SENASEM) laboratories rehabilitated; (v) 32 sources of drinking water provided; (vi) four animal containment areas with paddocks and water troughs; and (vii) 94 markets and storage facilities are being constructed with financing from the African Development Bank in the provinces of Katanga, East Kasai, West Kasai, Bandundo, and Bas-Congo.

In addition, 702 tractors and 30 cultivators were acquired and sent to all provinces and selected National Institute for Agronomy Research (INERA) stations. Also noteworthy are the purchase of 85 pair of draught animals and training of 125 pair of show animals and 410 pair of farm animals. These actions served to maintain the agriculture and rural development sector share in GDP at roughly 3 percent.

Despite the above outcomes, the agriculture and rural development sector continues to face significant challenges in terms of access to markets and credit, particularly for investments; access to technology and quality plant products; access to land and land management; and labor availability and productivity.

\subsubsection{Forest and the environment}

The government's policy in regard to forests is to rehabilitate the sector and promote sustainable management of flora and fauna to increase their contribution to the economic, social, and cultural development of present and future generations.

To this end, the Government established the following objectives: (i) combat desertification through sustainable management of lands and forests, (ii) promote awareness of forest laws; (iii) reduce emissions due to deforestation and degradation, (iv) improve the forest management information system, (v) strengthen the capacities of the ministry and its agencies, and (vi) administer a national action plan to adapt to climate change.

The government finalized the majority (some 30 of 42) of the implementing regulations under the forest code in 2009. At the same time, it strengthened commercial services and support to the Sustainable Land and Forest Management Board by establishing a national committee on forest and land degradation. Civil society stakeholders supported a number of local

\footnotetext{
3 Plans implemented in the context of restoring agricultural production and integrating and organizing rural production areas: the Emergency Multi-Sector Infrastructure Rehabilitation and Reconstruction Program (PMURR), the Agriculture and Rural Sector Rehabilitation Project in Katanga, West Kasai and East Kasai Provinces (PRESAR), the Agriculture and Rural Sector Rehabilitation Support Project in Bandundu and BasCongo Provinces (PARSAR), the Lake Tanganyika Integrated Regional Development Program (PRODAP), the Program in Support of Community Development Initiatives (PAIDECO), the Orientale Province Agricultural Recovery Program (PRAPO), the Equateur Province Agricultural Recovery Program (PRAPE), and the Emergency Social Action Plan (PASU).
} 
communities in concluding terms of reference for monitoring of forest management plans. To support implementation of the forest code, seminars and consultations were arranged as part of the participatory zoning process in the provinces of Equateur, Bandundu, and Orientale. Informational campaigns about the forest code were also conducted through the provincial administrative centers, with support from the United Nations Food and Agriculture Organization (FAO).

Monitoring to reduce emissions due to deforestation and degradation commenced in 2009 and continues, and the report on country preparation for this effort was finalized. A statistical forest information database was also created to strengthen the forest management information system.

In regard to strengthening the institutional capacities of the ministry and its agencies, selected staff were trained in data collection and monitoring activities concerning protected areas under the National Forest and Nature Conservation Project (PNFOCO). ${ }^{4}$ Additional technical office staff received training in forest oversight and management, land management, and biodiversity in the DRC and abroad (in China, Sweden, France, and Spain). Also noteworthy in connection with the World Bank Forest and Nature Conservation Project (PFCN) is a project being executed with funding from the German Agency for Technical Cooperation (GTZ) to provide institutional strengthening for the Congolese Nature Conservation Institute (ICCN).

In the area of adaptation to climate change, the government developed profiles of projects supporting recovery of the agricultural and rural sector in the context of its initiative on "environmental awareness for the agricultural and rural population." The project, an effort to raise awareness of cultural practices found harmful to biodiversity, is being carried out in the Bas-Congo and Bandundu provinces.

\subsubsection{Mines and hydrocarbons}

In the mining subsector, the strategy adopted by the government during implementation of the GPRSP sought to increase the subsector contribution to economic growth. The government's growth policy was built upon three pillars, promoting private capital, restoring production, and improving management.

To promote private capital, the government conducted informational and awareness-raising activities relating to the Mining Code and regulations and finalized the organizational and financial audits of the mining rights administrator (Cadastre Minier, CAMI). Workshops were organized in 2009, and the resultant recommendations are being incorporated into the Mining Code in connection with the mining promotion project (PROMINES). To support mining production, the Small-Scale Mining Support Department (SAESSCAM) was strengthened in its support and oversight role vis-à-vis small-scale operators, resulting in the deployment of provincial offices in the East and West Kasai, Katanga, and North and South Kivu.

To strengthen the capacities of sector enterprises, mining companies and related services were restructured, including (i) the state-owned mining company, GECAMINES, (ii) the Kilo Moto Gold Mining Office (OKIMO), and (iii) the Expertise, Evaluation, and Certification Center (CEEC). Additional entities are in the reorganization process. In addition, most of the mining

\footnotetext{
${ }^{4}$ The PNFOCO budget of US\$64 million is financed by the World Bank.
} 
contracts revisited were renegotiated. Also, in regard to implementing the principles of the Extractive Industries Transparency Initiative (ITIE), the first report for 2007 was produced in 2009 and is pending validation by an independent consultant.

Nevertheless, the sector continues to face major challenges: (i) lack of funds to finalize the deployment of SAESSCAN and CAMI, (ii) encouraging and promoting microcredit for artisanal operators and continuing informational activities in connection with the Mining Code, (iii) infrequent payment of agreed bonuses to ministry agencies, and (iv) lack of transparency on the part of certain companies in reporting revenues and payments to the government.

In the hydrocarbon subsector, the government intends to leverage petroleum and gas reserves to make the DRC one of the largest African producers. This effort will rely on: (i) reducing the risk of gas production, (ii) reducing the energy deficit in the eastern sub-region, and (iii) drafting the petroleum code.

In connection with reducing gas production risks, the government implemented an experimental, artificial lake degassing mechanism at the Gulf of Kabuno during 2009, pending complete degassing of the lake.

To offset the energy deficit in the eastern sub-region, the government signed a memorandum of understanding with private partners to produce methane gas. A joint Congolese-Rwandan entity was created to exploit the gas and produce electricity in North and South Kivu. The government also prepared a proposed hydrocarbon code and presented it to the Parliament in 2009 for adoption.

\subsubsection{Energy}

The initiatives in this sector primarily concerned the production and distribution of electricity. The government's aim is to increase access to reliable energy for all communities in all segments of society to increase coverage from 6 percent to 12.5 percent by 2015 , in line with the MDGs, 60 percent by 2025 , and ultimately to the entire national territory.

To this end, the government's actions focused on (i) improving the sector institutional and regulatory framework, (ii) investments to improve reliability, (iii) rehabilitation of existing infrastructures, (iv) development of new infrastructures, and (v) construction of distribution networks associated with the production centers.

The African Development Bank has arranged US\$15 million in financing to conduct reliability studies for development of the Inga site and related interconnections. A new electricity code was validated by stakeholders in 2009. An Energy Information System (SIE) was created to publish up to date information on the DRC's energy situation by June 2010.

Also, in connection with the PMEDE and SAPMP projects, ${ }^{5}$ the government undertook a large-scale investment program enabling it to implement and complete the following actions in 2009: (i) rehabilitation of the Inga plant, including Group 3, (ii) acquiring a Francis turbine

\footnotetext{
5 The Domestic Electricity Markets for Consumption and Export Project (PMEDE) and the Southern Africa Power Market Project (SAPMP) are jointly financed for US\$900 million by the World Bank, the European Investment Bank, and the African Development Bank.
} 
runner for Inga 2B, (iii) completing a rehabilitation study for the Zongo plant, and (iv) installing a $500 \mathrm{KVA}$ floating hydropower plant at Kananga.

\subsubsection{Transportation infrastructure}

With support from the development partners, ${ }^{6} 22,900.60$ kilometers of roads were completed of a planned 20,352.05, representing 113 percent of the objective. The principal actions related to modernization, rehabilitation, re-opening of unpaved and rural roads, and largescale infrastructure maintenance.

\section{Box 5. Selected highway infrastructure actions}

A number of roads were rehabilitated during the last 12 months or are in the process of construction. These include the Kenge-Kikwit, Lubumbashi-Kasumbalesa, Beni-Kisangani, and Mbandaka-Bikoro segments. Rehabilitation work was also begun on the Bukavu-Kavumu, Kamituga-Kasongo, Kisangani-Banalia-ButaBunduki and Lisala-Bumba-Bunduki segments and is well under way at this time. Work is beginning on the Ilebo-Kananga, Kikwit-Tshikapa-Kananga-MbujiMayi-Kabinda-Kasongo, Uvira-Fizi-Kalemie-PwetoKasomeno, Beni-Lubero-Rutshuru-Goma, and Niania-Isiro roads. Travel times and costs of road transportation have declined significantly. Also, to complement the rehabilitation efforts on agricultural feeder roads, 20 ferries were built or rehabilitated and deployed in Bandundu, Equateur, and East and West Kasai.

In the railroad sector, repairs were completed on a number of arteries in the city and province of Kinshasa. Additional projects under way aim to rehabilitate 300 kilometers of railroad track in the capital. The National Highway Maintenance Fund (FONER) also began operations.

In regard to airport infrastructures, work began on the runway and main pavilion of the N'djili Airport.

The following table summarizes achievements in the highway sector.

Table 1. Summary of highway sector outcomes

\begin{tabular}{lrrr}
\multicolumn{1}{c}{ Description } & $\begin{array}{c}\text { Planned } \\
\text { (in Km) }\end{array}$ & $\begin{array}{c}\text { Completed } \\
\text { (in Km) }\end{array}$ & \multicolumn{1}{c}{$\%$} \\
General-purpose roads & $\mathbf{1 0 , 7 9 3 . 6}$ & $\mathbf{5 , 0 0 0}$ & $\mathbf{4 6}$ \\
- Paid from own funds & 438 & 158 & 36 \\
- Paid with external funds * & $10,355.6$ & 4,842 & 47 \\
\hline Urban railways & $\mathbf{1 5 8 . 4 5}$ & $\mathbf{8 3 . 9}$ & $\mathbf{5 3}$ \\
- Paid from own funds & 107.25 & 58 & 54 \\
- Paid with external funds* & 51.20 & 25.9 & 51 \\
\hline Rural roads & $\mathbf{9 , 4 0 0}$ & $\mathbf{1 7 , 8 1 7}$ & $\mathbf{1 9 0}$ \\
- Paid from own funds & - & - & - \\
- Paid with external funds & 9,400 & 17,817 & 190 \\
\hline TOTAL & $\mathbf{2 0 , 3 5 2 . 0 5}$ & $\mathbf{2 2 , 9 0 0 . 9}$ & $\mathbf{1 1 3}$ \\
\hline Source: & & & \\
Calculations based on information obtained from the Agricultural Feeder Roads Department \\
(DVDA), the Highway Authority (ODR), the Road Network and Drainage Authority (OVD), and \\
the Large-Scale Works Agency (AGT). \\
* includes the Sino-Congolese program.
\end{tabular}

\footnotetext{
${ }^{6}$ The main partners involved in this sector are the African Development Bank, through PARSAR; the Kingdom of Belgium; and the World Bank, through PMURR.
} 
Since the completion of rehabilitation work on State Route 4 (RN4) between Kisangani and Beni (in north Kivu), the resumption highway traffic has eclipsed the airplanes which until then had transported most goods in this part of the area, located in the eastern part of the Democratic Republic of Congo (DRC). In the center of Butembo, mattresses wrapped in plastic, baskets full of onions, garlic, and assorted commodities are strewn along the stadium avenue. Amid the chaos, warehouse workers load sacks of beans onto heavy vehicles, each labeled "Kisangani Express."

"There is always a vehicle to be loaded. That's how we earn a living here," said Bamimbi Vumi, a loader, straining to catch his breath. A makeshift parking lot was set up in late 2008, just beside the branch office of the largest ground transport company that transports passengers and goods between Butembo and Kisangani. Just months ago, only a few passengers would jostle one another to board vehicles and travel the $900 \mathrm{~km}$ that separates the two cities.

\section{Air carriers losing market share}

Before the road was rehabilitated, most passengers and goods travelled by air. Air carriers ruled. But demand for air transport has been in freefall since the completion of the road, for which the World Bank provided US\$55 million in financing through the Emergency Economic and Social Reunification Support Project (PUSPRES). A visit to the empty hangars of the few airline companies that still resist the arrival of vehicles reveals the effects of the competition. "Vehicle operators in Kisangani are really killing our business," complained Dominique Mbavumoja, branch manager for Mango Airlines, a local operator. "We are on the verge of folding, but are thinking up strategies to retain our clients."

Of the 13 airline companies operating between 2000 and 2005, only three are still trying to stay afloat. "What do you expect? Clients see where their interests lie. And besides, our government banned Antonov flights some time ago," said Pascal Karungu, vice-president of the Drivers' Association of Congo (ACCO). In his view, air transport "benefited foreign pilots more than anyone, but now it's our drivers who are profiting." "We used to charge US\$1.4 per kilo, but the truck drivers came along and lowered the price to US\$0.5 per kilo. Some even go as low as US\$0.25," said Muyisa Kambine, head of marketing for Galaxie Kavatsi airline. "Before the truckers came along, we handled between 150 and 200 tons of goods per month through Kisangani. Now it's around 29 metric tons," said Dominique Mbafumoya, bitterly.

Source: World Bank document.

\subsubsection{Industry}

The government's objective is to make the industrial sector competitive, create jobs, and fully integrate the sector in regional and international trade.

To date, the Ministry of Industry has issued the first draft of the Industrial Policy and Strategy Document (DPSI), which is pending adoption and implementation, and prepared action plans for agro-industry and construction materials, the priority segments.

In regard to management and oversight of legal standards of measurement in the DRC, 217 standards were adopted in agrifood (134 standards), units of measurement (13 standards), common cements (11 standards), wood (13 standards), steel (54 standards), and compliance assessment (one standard). A preliminary proposed law on standards of measurement was validated by an inter-ministerial commission and is pending adoption by the Council of Ministers. The government began construction of the Orientale Province cement plant, completed a study on pilot agrifood plants in Kalemie, North Kivu and Bas-Congo, and established a representational office for the Bas-Congo - Kinshasa development corridor. It also presented and defended before Parliament a proposed law to preserve national industry; promulgation of the law, establishment of the regulatory authority, and the choice of N'sele as the initial site for the proposed Special Economic Zones. 


\subsubsection{Trade}

The government contracted a trade integration assessment with support from the World Bank in order to compile the information on which to base its trade policy and global strategy to support trade. The preliminary conclusions of the study were made public at a conference in February 2010.

\subsection{Improved access to basic social services and reduced vulnerability}

\subsubsection{Education}

The government's policy for this sector is to develop an inclusive, effective educational system to promote economic growth, combat poverty, and promote peace and active, democratic citizenship. The government's objective was to raise the primary school enrollment rate from 64.1 percent to 80 percent during 2006-2008. This policy was implemented by strengthening leadership in the educational system, expanding access, and improving equity and quality at all educational levels.

A strategic framework for tuition-free primary, secondary, and professional education was developed, and the primary, secondary, and professional education strategy was adopted. Under the social component of the PMURR, financed by the World Bank, 140 schools were rehabilitated. As part of the Emergency Social Action Project (PASU) funded by the Social Fund of the Democratic Republic of the Congo (FSRDC) and TFPs, the government issued educational kits to primary school teachers and students and provided teacher guides to supplement reading and mathematics textbooks during 2006-2009. Also, with financing from the World Bank and the Belgian Technical Cooperation (BTC), textbooks were provided for primary school students.

As a result of these actions, the gross primary school enrollment rate increased from 64.1 percent in 2006 to 84.3 percent in 2008, compared to 80 percent projected in 2005 . However, enormous challenges remain in regard to meeting the constitutional standard of universal, tuition-free primary education and achieving the MDGs.

\subsubsection{Health}

The government's policy in this sector is to provide access to quality healthcare for all citizens, particularly vulnerable groups, and combat major epidemics and communicable diseases. The expected outcome of this objective is a reduction in the infant mortality rate from 126 per 1,000 live births in 2001 to 89 in 2008, and reduction of the maternal mortality rate from 1,289 to 944 per 100,000 births over the same period.

To achieve these outcomes, the government took the following actions: ${ }^{7}$ (i) adopted transitional measures to support the decentralization process, (ii) prepared health sector

\footnotetext{
7 These actions were carried out with technical and/or financial support from the following development partners: the World Bank Health Sector Reform Project (PARSS), the World Health Organization (WHO), the Japan International Cooperation Agency, the United Nations Children's Fund, the United Nations Population Fund, the Global Fund, the United States Agency for International Development (USAID) AXxes project, the 9th European Development Fund Health Program (PS9FED), GAVI, the GTZ, and the Belgian Intermediate and Central Health System Support (ASNIC) and Intermediate and Peripheral Health System Support (ASNIP) projects.
} 
facility inventories, a demographic and health survey (EDS), and a survey of the capacity of training establishments nationwide to generate data for the national policy review, rolled out the National Health Development Program (PNDS), and updated the Health System Strengthening Strategy (SRSS) and national health map (carte sanitaire), (iii) in connection with reform of the public administration, conducted an institutional audit with support from the WHO, and (iv) revised and disseminated health standards and directives.

In addition to regulatory actions, several initiatives targeted illnesses and disease: (i) the polio vaccination campaign and distribution of vitamin A and mebendazole to improve child health; (ii) a campaign to distribute insecticide-treated mosquito nets; and (iii) the vaccination of 2 million infants under age one with financial support from GAVI and UNICEF.

In December 2009, the government began construction work on a large 500-bed hospital in Kinshasa.

Several additional actions produced the following outcomes: (i) the under-five mortality rate declined over the reporting period from 172 to 165 per thousand, and thereafter to 148 per thousand; (ii) the neonatal mortality rate stabilized at roughly 38 per thousand; and (iii) the BCG vaccination coverage rate increased from 53 to 72 percent, DTP3 from 30 to 45 percent, Polio 3 from 42 to 46 percent, and the proportion of children who have completed the recommended vaccines increased from 23 to 31 percent.

\subsubsection{Water and sanitation}

The government's objective is to increase drinking water coverage from 22 percent in 2005 to 26.9 percent in 2008 , with the aim of reaching 40 percent by 2015 . The efforts to reach this objective will include: (i) strengthening and developing drinking water supply systems and restoring the capacities of the Water Distribution Authority (REGIDESO); (ii) rehabilitating existing infrastructures; (iii) drilling wells and collecting water from rural sources; (iv) improving management of water supply facilities; and (v) rehabilitating sewage lines in large cities.

The following actions ${ }^{8}$ were taken in regard to urban and rural drinking water supplies: (i) delivery of drinking water to several neighborhoods bordering East Kinshasa; (ii) construction of 19 wells, 14 in Kabalo and five in neighborhoods outside East Kinshasa; (iii) rehabilitation of a water collection facility at the Lukaya water treatment plant; (iv) rehabilitation of N'djili water collection facilities; (v) construction of a second module at the Boma collection plant and rehabilitation of the Kinshasa training center, maintenance shop, and central lab; and (vi) rehabilitation of secondary and tertiary networks in 10 communes of Kinshasa. Out of 32 projects identified, seven were completed for a cost evaluated at US\$423 million compared to US\$428 million, representing a financial execution rate of 99 percent.

\footnotetext{
8 The following partners provided support in the water and sanitation sector: the World Bank, the African Development Bank, the European Union, UNICEF, the German Development Cooperation (KFW Development Bank), and Belgian Development Cooperation / Belgian Export Financing (FINEXPO), in connection with the Emergency Urban and Social Rehabilitation Project (PURUS), the Urban Water Supply Project (PEMU), the Multi-Sector Socioeconomic Infrastructure Rehabilitation Project (PMURIS), the Peri-Urban Water Supply and Sanitation Project (PEASU), PMURR, and others.
} 
The government actions served to increase access to drinking water to a rate currently estimated at 27 percent.

However, a number of difficulties were encountered in implementing actions in this sector:

- lack of a water and sanitation sector development strategy;

- weak progress in legal and institutional sector reforms;

- nonalignment of several actions planned in the government budget;

- insufficient financial resources to make use of investments (government counterpart for implementation of projects financed by external partners);

- weak alignment of external financing with government priorities; and

- weak technical and financial capacities of local enterprises to carry out works.

\subsubsection{Social protection}

The government's objective in this sector is to improve living conditions for vulnerable groups, women and children in difficulty, persons living with handicaps, the elderly, and displaced persons and/or refugees. To achieve its objectives, the government conducted informational and awareness campaigns regarding the social protection strategy, community development, and creation of wealth adapted to the situation of target groups.

The principal actions implemented were: (i) adoption and publication of the child protection law; (ii) provincial consultations and development of a document on child protection in case of divorce or family separation; (iii) the removal of 12,000 children working in mines; (iv) reintegration of 570 youths affected by the war; (v) the adoption of policies and a national action plan on orphans and vulnerable children; (vi) a census of street children in Kinshasa, estimated to number 14,000; and (vii) the development of training modules for social workers and capacity-strengthening activities for 130 social workers in four provinces (Kinshasa, East Kasai, Katanga, and Bandundu).

\subsection{The fight against HIV/AIDS (one of the GPRS pillars)}

The government's policy is to: (i) prevent the transmission of HIV; (ii) improve the quality of life for persons living with HIV; (iii) mitigate the impact of AIDS on the community; and (iv) strengthen coordination, monitoring, and evaluation at all levels.

The actions taken to achieve these results concerned preventing and treating HIV/AIDS, attenuating the socioeconomic impact of HIV/AIDS, and strengthening coordination and monitoring-evaluation actions in the fight against HIV/AIDS.

\subsubsection{Preventing and stabilizing HIV and STI transmission}

This component was central to the government's efforts. Awareness and mobilization campaigns were conducted to encourage communities to change behaviors relating to vulnerability factors. These included informal educational talks and activities to promote STI services, voluntary counseling and screening, and the use of condoms by specific vulnerable populations (sex workers, persons living with HIV, men in uniform, transport workers, miners, truck farmers, etc.).

Fifty million condoms were distributed per year in recent years, and 220 million were ordered in 2009. The rate of use remains low, however, and the estimated rate of use among teenagers 
is estimated at 21 percent. A number of initiatives targeting the young were also conducted, including efforts to delay the start of sexual activity, promote monogamous relationships, and promote proper use of condoms. In addition, approximately 4,098,750 individuals received comprehensive services between 2007 and 2009, including test results, voluntary counseling and screening to raise awareness of individual vulnerability, and early treatment of persons living with HIV.

During the same period, 642,096 out of 1,674,330 IST cases were treated in accordance with national directives, representing 38 percent coverage of requirements (National Multi-Sector Program against HIV/AIDS (PNMLS) annual reports, 2007-2009) as illustrated in the graph below.

As the following graph shows, there was a slight change in terms of coverage, although the gap persists. In total, from 2007 to $2009,98.7$ percent of pregnant women did not receive prophylactic antiretroviral (ARV) therapy to prevent mother-to-child transmission.

The proportion of infants born to HIV-positive mothers who were also infected by HIV was 25 percent (National Multi-Sector Program against HIV/AIDS (PNMLS), United Nations General Assembly Special Session on HIV/AIDS (UNGASS), 2007).

Figure 5. Preventing mother-to-child transmission: 2007-2009 coverage

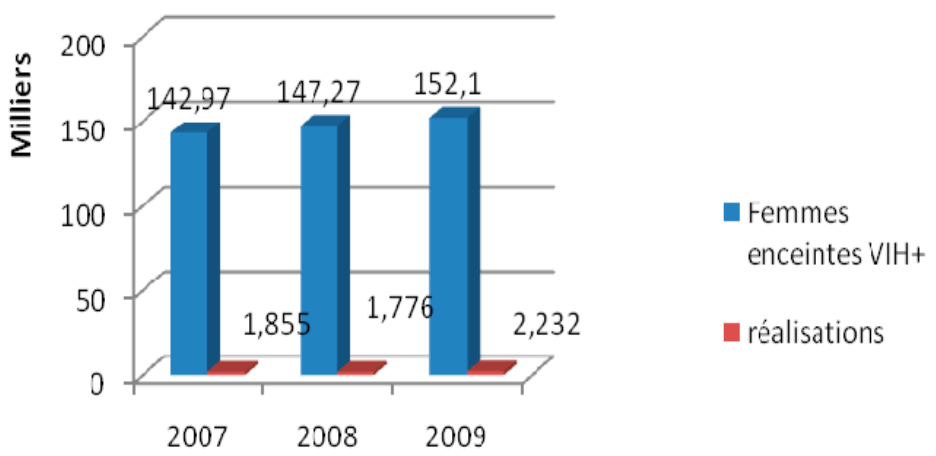

[Key:]

Y axis: thousands

Blue: HIV-positive pregnant women

Red: [Treatments]

In addition, to reduce the risk of HIV transmission, the government distributed post-exposure prophylactic kits to female victims of sexual violence, and continued regular programming and distribution of condoms to vulnerable groups. In 2008, over 18,407 incidents of sexual violence were recorded in the DRC, and only 2,254, or 14 percent, had access to postexposure kits, 9 revealing an 86 percent gap in terms of victims of sexual violence with access to post-exposure kits to prevent HIV. Also, several million condoms were distributed throughout the DRC.

9 United Nations Population Fund (UNFPA), 2008 annual report. 
In regard to safety of transfusions, the government's intent remains to expand coverage to populations in need while ensuring the quality of transfused blood. In regard to the figure below, only 686,379 blood transfusions of the stated need $(1,136,000)$ occurred in three years, representing 60.42 percent coverage. When quality screening aspects are taken into account, including compliance with the national protocol, training of transfusion service providers, and quality control, the 2007 UNGASS report indicates that only 46.8 percent of transfused blood units underwent quality screening.

\subsubsection{Speeding treatment and improving the quality of life of persons living with HIV/AIDS}

In order to improve the quality of life of persons living with HIV, the government provided ARV treatment to eligible persons living with HIV as well as treatment for opportunistic infections (OI). In 2009, 34,947 patients from Kinshasa (11,701), Kisangani (4,751), and Katanga $(3,041)$ received ARV treatment, compared to only 15,561 persons treated in 2006.

Until 2008, treatment of OIs was provided in only 33.6 percent of health zones, representing a coverage gap of 64.4 percent. To date, 15 percent of health zones, or 80 out of a total of 515 , provide care for HIV-tuberculosis co-infection. Out of 100,000 cases detected each year, 97 percent did not have access to HIV screening, and over 60 percent of those infected did not receive ARV therapy. In 2009, 56,563 new OI cases were recorded. Tuberculosis, with 5,161 cases (PNMLS annual report, 2009), is the most widespread opportunistic infection. The estimated percentage of persons with HIV/TB co-infection who received both TB and [HIV] therapy was 0.1 percent (PNMLS, UNGASS Report 2007).

\subsubsection{Mitigating the socioeconomic impact of HIV/AIDS on the community}

To prepare a strategy to support orphans and vulnerable children (OVCs) data collection workshops were organized in connection with the Rapid Country Assessment, Analysis, and Action Planning Initiative on Behalf of Orphans and other Vulnerable Children in Sub-Sahara Africa (RAAAP). As a result, 135,708 OVCs identified were enrolled in school, 53,418 received nutritional assistance, and 87,124 received legal assistance. Also, in the public sector, the HIV/AIDS offices 17 ministries and the national assembly prepared and implemented national and provincial operational plans to combat HIV/AIDS.

In the private sector, the following services were offered: (i) treatment of STIs; (ii) distribution of condoms; and (iii) ARV treatment. Regarding educational efforts, HIV education was included in the primary school curriculum.

Also, to strengthen the legal framework for persons living with HIV, a law on protection of persons living with HIV and other affected persons was published on July 14, 2008. The law requires the government to make available medicines for the treatment of AIDS and HIV screening tests free of charge, and expands the government's responsibilities in combating expansion of the pandemic through a more coherent policy for treatment of affected persons and sanctions for discrimination against them.

\subsubsection{Building coordination, monitoring and evaluation capacities at all levels}

In 2009, the National Multi-Sector Commission to Combat AIDS (CNMLS) adopted the 2010-2014 National Strategy to Combat AIDS. In order to speed implementation of the 
strategy, two sector plans to combat AIDS were developed for the health and education sector.

\subsection{Support for local initiatives}

In connection with the PASU program, the government rehabilitated public infrastructures in selected communities using the high labor intensive (HLI) approach, and strengthened social security. In the same context, selected communities in 11 provinces received micro-grants, information, education, and communication campaigns, training sessions, and technical advisory services for project monitoring and evaluation.

\subsection{Strengthening capacities}

No integrated capacity-strengthening programs were carried out during the GPRS implementation period. To remedy this situation, the National Capacity Strengthening Secretariat (SENAREC) was directed to implement a National Capacity Strengthening Program (PRONAREC). The program is to be included in the 2011-2015 Five-Year Development Plan.

\section{Chapter 3. MONITORING AND EVALUATION}

The GPRS provides for an institutional mechanism to coordinate implementation and tools to provide monitoring and evaluation.

\subsection{Institutional framework}

The institutional coordinating structure for the GPRS includes the Inter-Ministerial Commission on the National Poverty Reduction Strategy (CI-SNLCP) and its technical arm, the National Poverty Reduction Strategy Coordinating Unit (UPPE-SRP); and the InterMinisterial Monitoring Commission for Financial Institution Programs (CISPI) and its Technical Monitoring Committee (CTR). In addition to these bodies are institutions such as the INS, the Congolese Poverty and Inequality Observatory (OCPI) and the Aid and Investment Management Platform (PGAI).

Thematic groups were instituted in 2008 to serve as framework for consultations between the government, the TFPs, and civil society organizations in implementing the actions provided in the GPRS.

In the provinces, implementation of the GPRS was coordinated by the provincial executive, with technical support from provincial and local committees and cooperation from the TFPs.

All of the coordination structures supporting GPRS implementation were placed under the authority of the prime minister. The strategic coordination proved less than satisfactory at the central and provincial levels. However, the implementation, monitoring, and evaluation activities of sector structures performed well with support from the TFPs. In mid-2009, the government promoted corrective action by instituting weekly meetings to monitor progress on HIPC Initiative completion point triggers. 


\subsection{Monitoring and evaluation tools}

For the purpose of monitoring and evaluating the GPRS, appropriate indicators were defined in the sectors identified as priorities under the first-generation GPRSP. These were the education, health (including HIV/AIDS), agriculture, rural development, transportation infrastructure, and water and sanitation sectors.

The indicators were derived from the 1-2-3 surveys (2004-2005), the Multiple Indicator Cluster Survey II (MICS 2) (2001), and participatory consultations (2004-2005). No other major surveys have been conducted since 2006 other than the Demographic and Health Surveys (EDS) to measure comparative progress in regard to the MDGs.

With respect to macroeconomic performance, the indicators were established in the context of the IMF staff monitoring program and the program currently being supported by the Poverty Reduction and Growth Facility (PRGF). Other indicators were defined as projects or sector programs were being designed.

It should be noted that weaknesses in the Congolese statistical apparatus precluded the monitoring of most indicators during execution of the GPRS, which would have enabled the necessary adjustments to be made during implementation of the GPRS.

However, midterm reviews of portfolio performance conducted, inter alia, by the World Bank, the African Development Bank Group, agencies of the United Nations and European Union, and several bilateral partners provided the DRC with indications on progress in the sectors benefiting from their interventions. 


\section{CONCLUSION}

\section{Closing remarks}

The Congolese government is pleased to have initiated an effort, with the support of its technical and financial partners, to systematize its medium-term development planning, and to have resolutely done so in a very hostile internal and external context. The results achieved are less important than the ultimate adherence to an approach that represents a clear break with ad hoc practices that marked years of poor governance.

Having reviewed the implementation of the GPRS, the government believes it has done so satisfactorily and has therefore accomplished Trigger No. 1 of the Completion Point under the HIPC Initiative. The first-generation GPRSP would have produced more successful results were it not for the constraints faced over the entire implementation period, chief among which were:

- Limited internal resources to finance the GPRS, due to government revenue remaining low despite a relatively high rate of growth. This situation was exacerbated by a contraction of budgetary support following suspension of the program supported by the PRGF, which slowed the pace of reforms;

- De-linking of the priority action plan (PAP), a key tool in implementing the GPRS, from the national budget, preventing it from being executed through the expenditure cycle. This situation is the result of lack of cohesion between the Budget Preparation and Monitoring Department, the Planning Department, and the sector ministries;

- Lack of communication between the government and the Bretton Woods institutions, which initiated the planning approach through the GPRSP, in regard to a tool being attempted for the first time in a country emerging from conflict. This situation did not advance the purpose of developing an understanding of the approach and adapting it;

- Burdensome administrative procedures imposed on project execution by both TFPs and the government, impacting project cost evaluations in most cases;

- Social and political uncertainties created by the tensions of the 2006 elections, exacerbated by the climate of insecurity in the eastern part of the country, and their repercussions for public financial management and macroeconomic stability;

- The international food and financial crises followed by the collapse of commodities prices, which had devastating effects on economic activity and the management of public finances and currency.

Despite the constraints identified above, implementation of the GPRS produced encouraging results, as summarized below:

- Social sector indicators (health, HIV/AIDS, education, water and sanitation) improved. The greatest gains were made in the education sector, where the various indicators are on par with those of sub-Saharan African countries. 
- The macroeconomic programs implemented during the period under review restored macroeconomic stability, as demonstrated by the conclusion of the IMF program known as PEG II, supported by the PRGF, in December 2009. However, the modest performance observed in regard to budgetary and monetary policies could have been strengthened if the reform program had not slowed, in which case the macroeconomic policies would have made a significant contribution toward reducing poverty.

- The emergency sector programs, projects, and actions in the areas of planning, security, transportation infrastructure, health, education, and water have restored peace and security and improved socioeconomic conditions, albeit slightly, for the Congolese people. They had a genuine impact on poverty reduction, primarily in terms of improved economic and social infrastructures and access to basic social services. The results described represent the execution of only half of the actions planned.

- The government recognizes that the strategic coordination of the GPRS was not commensurate with the importance of the issues at stake. It notes, however, that the weekly meetings instituted in the second half of 2009 to monitor progress on the HIPC Initiative completion point triggers signal a new direction in adapting government programs. In this regard, the government expects to intensify and rationalize its efforts in the context of the second-generation GPRSP.

\section{Recommendations}

The recommendations draw on the lessons learned from implementation of the firstgeneration GPRSP. They shed light on the options that could emerge from the participatory consultations on the second-generation GPRSP. Certain GPRSP pillars, noted below form the basis of tomorrow's challenges:

1. Consolidating peace and security, through continued actions to complete the pacification of national territory and end the humanitarian crisis, and by accelerating reform of the security sector;

2. Expanding the government's capacity to deliver quality social services by creating consensus as to the government's role and the need to better focus that role on its sovereign missions, and adapt the central and provincial administrations accordingly;

3. Promoting administrative and economic governance by continuing the decentralization process, adjusting it to our means; through a relationship of accountability between government and the governed; through continued financial reforms and reforms of public enterprises; and through a genuine commitment to transparent mechanisms in managing natural resources (EITI++);

4. Strengthening the conditions for sustainable growth, through an improved business climate and implementation of a roadmap to raise the country's standing in the "Doing Business" category; intensified support for sectors with growth potential and the road, energy, and transportation infrastructures; and implementation of an aggressive commercial policy; 
5. Giving serious consideration to the effects of climate change and issues pertaining to nature conservation; and

6. Mobilizing the private sector (including through public-private partnerships) to address the problems of financing development programs.

In reference to the important task of monitoring and evaluation, the government will face six major challenges: (i) reviewing and formalizing the monitoring-evaluation framework; (ii) securing the production of statistical data; (iii) renewing the operational and budgetary programming framework; (iv) implementing reporting tools: (v) developing a minimal framework for evaluating public policies; and (vi) increasing participation and communication. 


\section{ANNEXES}

1. Summary budget by function, 2008-09

2. Summary budget by category of expenditure, 2008-09

3. Summary budget by GPRSP pillar, 2008-09

4. Tables on macroeconomic framework

5. Millennium Development Goal Indicators

6. Priority actions: 2009 outcomes and 2010 programming 
Table 1.1. Democratic Republic of the Congo - Summary budget by function, 2008-09 (CGF billions)

\begin{tabular}{|c|c|c|c|c|}
\hline & 2008 & & 2009 & \\
\hline & Actual & Budget & Actual & $\begin{array}{r}\text { Execution } \\
\text { rate }\end{array}$ \\
\hline Grand total primary expenditure & $1,514,680$ & $2,552,880$ & $1,701,365$ & 66.6 \\
\hline Central public administration (excluding public debt) & 624,754 & 904,352 & 682,060 & 75.4 \\
\hline Defense & 141,016 & 156,168 & 224,585 & 143.8 \\
\hline Order and public security & 125,276 & 120,812 & 107,375 & 88.9 \\
\hline Economic affairs & 254,098 & 763,497 & 288,521 & 37.8 \\
\hline Protection of environment, flora and fauna & 8,091 & 50,728 & 7,824 & 15.4 \\
\hline Social protection, social affairs & 26,162 & 38,748 & 22,990 & 59.3 \\
\hline Lodging and utilities & 41,975 & 57,417 & 35,082 & 61.1 \\
\hline Health & 69,635 & 161,580 & 99,517 & 61.6 \\
\hline Religions, culture, sports and recreation & 16,910 & 15,170 & 22,208 & 146.4 \\
\hline Education & 206,765 & 284,409 & 211,205 & 74.3 \\
\hline & \multicolumn{4}{|c|}{ (Percentage of GDP) } \\
\hline Grand total primary expenditure & 23.2 & 32.9 & 19.5 & $\ldots$ \\
\hline Central public administration (excluding public debt) & 9.6 & 11.7 & 7.8 & $\ldots$ \\
\hline Defense & 2.2 & 2.0 & 2.6 & $\ldots$ \\
\hline Order and public security & 1.9 & 1.6 & 1.2 & $\ldots$ \\
\hline Economic affairs & 3.9 & 9.8 & 3.3 & $\ldots$ \\
\hline Protection of environment, flora and fauna & 0.1 & 0.7 & 0.1 & $\ldots$ \\
\hline Social protection, social affairs & 0.4 & 0.5 & 0.3 & $\ldots$ \\
\hline \multirow{2}{*}{ Lodging and utilities } & & & & \\
\hline & 0.6 & 0.7 & 0.4 & ..1 \\
\hline Health & 1.1 & 2.1 & 1.1 & $\ldots$ \\
\hline Religions, culture, sports and recreation & 0.3 & 0.2 & 0.3 & $\ldots$ \\
\hline Education & 3.2 & 3.7 & 2.4 & $\ldots$ \\
\hline \multicolumn{5}{|c|}{ (Percentage of total primary expenditure, unless otherwise indicated } \\
\hline Grand total primary expenditure & 100.0 & 100.0 & 100.0 & $\ldots$ \\
\hline Central public administration (excluding public debt) & 41.2 & 35.4 & 40.1 & $\ldots$ \\
\hline Defense & 9.3 & 6.1 & 13.2 & $\ldots$ \\
\hline Order and public security & 8.3 & 4.7 & 6.3 & $\ldots$ \\
\hline Economic affairs & 16.8 & 29.9 & 17.0 & $\ldots$ \\
\hline Protection of environment, flora and fauna & 0.5 & 2.0 & 0.5 & $\ldots$ \\
\hline Social protection, social affairs & 1.7 & 1.5 & 1.4 & $\ldots$ \\
\hline Lodging and utilities & 2.8 & 2.2 & 2.1 & $\ldots$ \\
\hline Health & 4.6 & 6.3 & 5.8 & $\ldots$ \\
\hline Religions, culture, sports and recreation & 1.1 & 0.6 & 1.3 & $\ldots$ \\
\hline Education & 13.7 & 11.1 & 12.4 & $\ldots$ \\
\hline \multicolumn{5}{|l|}{ For reference: } \\
\hline Nominal GDP (CDF billions) & $6,525,983$ & $7,760,000$ & $8,729,320$ & $\ldots$ \\
\hline Total expenditure & $1,635,292$ & 2,922,394 & $1,846,675$ & \\
\hline Public debt (CDF billions) & 120,612 & 369,513 & 145,310 & $\ldots$ \\
\hline
\end{tabular}

Source: Budget monitoring reports, printed April 7, 2010 
Table 1.2. Democratic Republic of the Congo. Summary budget by category of expenditure, 2008-09 (CDF billions)

\begin{tabular}{|c|c|c|c|c|}
\hline & 2008 & & 2009 & \\
\hline & Actual & Budget & Actual & $\begin{array}{r}\text { Execution } \\
\text { rate }\end{array}$ \\
\hline Grand total primary expenditure & $1,515,072$ & $2,552,888$ & 1,701365 & 67 \\
\hline Operations & $1,208,303$ & $1,589,538$ & 1,325330 & 83 \\
\hline Personnel & 533,641 & 590,116 & 559789 & 95 \\
\hline Excluding personnel & 674,662 & 999,422 & 765541 & 77 \\
\hline Goods and materials & 100,620 & 44,020 & 65724 & 149 \\
\hline Service expenditures & 153,897 & 58,677 & 137715 & 235 \\
\hline Government transfers and interventions & 420,145 & 896,725 & 562103 & 63 \\
\hline Investment & 306,769 & 963,350 & 376035 & 39 \\
\hline \multicolumn{5}{|c|}{ (Percentage of GDP) } \\
\hline Grand total primary expenditure & 23.2 & 32.9 & 19.5 & \\
\hline Operations & 18.5 & 20.5 & 15.2 & $\ldots$ \\
\hline Personnel & 8.2 & 7.6 & 6.4 & $\ldots$ \\
\hline Excluding personnel & 10.3 & 12.9 & 8.8 & $\ldots$ \\
\hline Goods and materials & 1.5 & 0.6 & 0.8 & $\ldots$ \\
\hline Service expenditures & 2.4 & 0.8 & 1.6 & $\ldots$ \\
\hline Government transfers and interventions & 6.4 & 11.6 & 6.4 & $\ldots$ \\
\hline Investment & 4.7 & 12.4 & 4.3 & $\ldots$ \\
\hline \multicolumn{5}{|c|}{ (Percentage of total primary expenditure) } \\
\hline & & & & \\
\hline Operations & 79.8 & 62.3 & 77.9 & \\
\hline Personnel & 35.2 & 23.1 & 32.9 & $\ldots$ \\
\hline Excluding personnel & 44.5 & 39.1 & 45.0 & \\
\hline Goods and materials & 6.6 & 1.7 & 3.9 & $\ldots$ \\
\hline Service expenditures & 10.2 & 2.3 & 8.1 & $\ldots$ \\
\hline Government transfers and interventions & 27.7 & 35.1 & 33.0 & $\ldots$ \\
\hline Investment & 20 & 39 & 22 & \\
\hline \multicolumn{5}{|l|}{ For reference: } \\
\hline Total expenditure & $1,635,292$ & $2,922,394$ & 1,846675 & 63 \\
\hline Public debt, principal & 120,612 & 369,513 & 145310 & 39 \\
\hline Nominal GDP (CDF billions) & $6,525,983$ & $7,760,000$ & 8,729320 & ... \\
\hline
\end{tabular}

Source: Budget monitoring reports, printed April 7, 2010 
Table 1.3. Democratic Republic of the Congo. Summary budget by GPRSP pillar, 2008-09 (CDF billions)

\begin{tabular}{|c|c|c|c|c|}
\hline & 2008 & & 2009 & \\
\hline & Actual & Budget & Actual & $\begin{array}{l}\text { Execution } \\
\text { rate }\end{array}$ \\
\hline Grand total primary expenditure & $1,514,680$ & $2,552,880$ & $1,701,365$ & 66.6 \\
\hline Good governance and peace (excluding public debt) & 891,563 & $1,157,332$ & $1,018,361$ & 88.0 \\
\hline Political and administrative governance & 359,279 & 728,150 & 338,952 & 46.5 \\
\hline Security governance & 260,353 & 247,103 & 330,400 & 133.7 \\
\hline Economic governance (excluding public debt) & 271,932 & 182,079 & 349,009 & 191.7 \\
\hline Support for sectors with economic growth potential & 245,859 & 752,213 & 281,059 & 37.4 \\
\hline Agriculture, forestry, hunting and fishing & 31,216 & 48,189 & 59,331 & 123.1 \\
\hline Buildings and public works & 18,783 & 21,841 & 8,206 & 37.6 \\
\hline Electricity & 37,800 & 34,670 & 7,892 & 22.8 \\
\hline Hydrocarbons & 26,993 & 10,975 & 10,514 & 95.8 \\
\hline Extractive industries & 17,396 & 9,275 & 5,830 & 62.9 \\
\hline Manufacturing industries & 1,202 & 6,726 & 3,483 & 51.8 \\
\hline Goods and services & 1,591 & 3,534 & 2,293 & 64.9 \\
\hline Telecommunications & 9,488 & 14,226 & 9,256 & 65.1 \\
\hline Transportation & 101,389 & 602,776 & 174,254 & 28.9 \\
\hline Access to basic social services & 377,258 & 643,335 & 401,944 & 62.5 \\
\hline Education & 206,765 & 284,499 & 211,205 & 74.2 \\
\hline Health & 69,635 & 161,580 & 99,517 & 61.6 \\
\hline Social protection & 33,883 & 73,942 & 26,109 & 35.3 \\
\hline Environment & 8,091 & 50,728 & 7,824 & 15.4 \\
\hline Water & 34,124 & 42,382 & 17,054 & 40.2 \\
\hline Electricity & 13 & 3,000 & 11,243 & 374.8 \\
\hline Urban poverty and habitat & 7,839 & 12,035 & 6,785 & 56.4 \\
\hline Culture, science, and universal access to technology & 16,910 & 15,170 & 22,208 & 146.4 \\
\hline & & \multicolumn{3}{|c|}{ (Percentage of GDP) } \\
\hline Grand total primary expenditure & 23.2 & 32.9 & 19.5 & 59.2 \\
\hline Good governance and peace (excluding public debt) & 13.7 & 14.9 & 11.7 & ... \\
\hline Political and administrative governance & 5.5 & 9.4 & 3.9 & ... \\
\hline Security governance & 4.0 & 3.2 & 3.8 & ... \\
\hline Economic governance (excluding public debt) & 4.2 & 2.3 & 4.0 & ... \\
\hline Support sectors with economic growth potential & 3.8 & 9.7 & 3.2 & ... \\
\hline Agriculture, forestry, hunting and fishing & 0.5 & 0.6 & 0.7 & ... \\
\hline Buildings and public works & 0.3 & 0.3 & 0.1 & ... \\
\hline Electricity & 0.6 & 0.4 & 0.1 & ... \\
\hline Hydrocarbons & 0.4 & 0.1 & 0.1 & .. \\
\hline Extractive industries & 0.3 & 0.1 & 0.1 & .. \\
\hline Manufacturing industries & 0.0 & 0.1 & 0.0 & ... \\
\hline Goods and services & 0.0 & 0.0 & 0.0 & .. \\
\hline Telecommunications & 0.1 & 0.2 & 0.1 & ... \\
\hline Transportation & 1.6 & 7.8 & 2.0 & ... \\
\hline Access to basic social services & 5.8 & 8.3 & 4.6 & ... \\
\hline Education & 3.2 & 3.7 & 2.4 & .. \\
\hline Health & 1.1 & 2.1 & 1.1 & ... \\
\hline Social protection & 0.5 & 1.0 & 0.3 & ... \\
\hline Environment & 0.1 & 0.7 & 0.1 & ... \\
\hline Water & 0.5 & 0.5 & 0.2 & .. \\
\hline Electricity & 0.0 & 0.0 & 0.1 & ... \\
\hline Urban poverty and habitat & 0.1 & 0.2 & 0.1 & ... \\
\hline Culture, science, and universal access to technology & 0.3 & 0.2 & 0.3 & \\
\hline (Percentage of $t$ & al expenditure & for pillar conce & ed, unless oth & ise indicated \\
\hline Good governance and peace (excluding public debt) & 100.0 & 100.0 & 100.0 & ... \\
\hline Political and administrative governance & 40.3 & 62.9 & 33.3 & \\
\hline Security governance & 29.2 & 21.4 & 32.4 & ... \\
\hline Economic governance (excluding public debt) & 30.5 & 15.7 & 34.3 & ... \\
\hline Support sectors with economic growth potential & 100.0 & 100.0 & 100.0 & ... \\
\hline
\end{tabular}




\begin{tabular}{|c|c|c|c|c|}
\hline Agriculture, forestry, hunting and fishing & 12.7 & 6.4 & 21.1 & \\
\hline Buildings and public works & 7.6 & 2.9 & 2.9 & \\
\hline Electricity & 15.4 & 4.6 & 2.8 & \\
\hline Hydrocarbons & 11.0 & 1.5 & 3.7 & \\
\hline Extractive industries & 7.1 & 1.2 & 2.1 & . \\
\hline Manufacturing industries & 0.5 & 0.9 & 1.2 & . \\
\hline Goods and services & 0.6 & 0.5 & 0.8 & . \\
\hline Telecommunications & 3.9 & 1.9 & 3.3 & .. \\
\hline Transportation & 41.2 & 80.1 & 62.0 & .. \\
\hline Access to basic social services & 100.0 & 100.0 & 100.0 & .. \\
\hline Education & 54.8 & 44.2 & 52.5 & .. \\
\hline Health & 18.5 & 25.1 & 24.8 & ... \\
\hline Social protection & 9.0 & 11.5 & 6.5 & .. \\
\hline Environment & 2.1 & 7.9 & 1.9 & .. \\
\hline Water & 9.0 & 6.6 & 4.2 & ... \\
\hline Electricity & 0.0 & 0.5 & 2.8 & ... \\
\hline Urban poverty and habitat & 2.1 & 1.9 & 1.7 & \\
\hline Culture, science, and universal access to technology & 4.5 & 2.4 & 5.5 & \\
\hline \multicolumn{5}{|l|}{ For reference: } \\
\hline Public debt (CDF billions) & 120612 & 369,513 & 145,310 & 39.3 \\
\hline Nominal GDP (CDF billions) & 6,525983 & $7,760,000$ & $8,729,320$ & \\
\hline
\end{tabular}

Source: Budget monitoring reports, printed April 7, 2010 
Table 1. Democratic Republic of the Congo: GDP at constant prices by sector of activity, 2006-09

\begin{tabular}{|c|c|c|c|c|}
\hline & $\begin{array}{c}2006 \\
\text { Est. }\end{array}$ & $\begin{array}{c}2007 \\
\text { Est. }\end{array}$ & $\begin{array}{c}2008 \\
\text { Est. }\end{array}$ & $\begin{array}{c}2009 \\
\text { Est. }\end{array}$ \\
\hline & \multicolumn{4}{|c|}{ (in constant CDF billions, base $100=2000$ ) } \\
\hline Primary sector & 204.3 & 210.5 & 221.3 & 226.1 \\
\hline Agriculture, forestry, hunting and fishing & 153.2 & 158.2 & 162.9 & 167.8 \\
\hline Extractive industries & 51.1 & 52.4 & 58.4 & 58.3 \\
\hline Secondary sector & 50.8 & 53.3 & 54.9 & 55.9 \\
\hline Manufacturing industries & 16.2 & 17.0 & 17.5 & 17.8 \\
\hline Buildings and public works & 31.8 & 33.5 & 34.8 & 35.4 \\
\hline Electricity, water & 2.8 & 2.9 & 2.7 & 2.7 \\
\hline Tertiary sector & 122.6 & 136.3 & 147.6 & 152.7 \\
\hline Wholesale and retail trade & 71.3 & 80.6 & 90.5 & 96.4 \\
\hline Transportation and communications & 22.3 & 24.7 & 26.8 & 27.8 \\
\hline Goods and services & 23.2 & 24.8 & 26.0 & 26.7 \\
\hline Public services & 7.7 & 8.2 & 8.5 & 6.2 \\
\hline Imputed production of bank services & -1.8 & -2.0 & -4.3 & -4.4 \\
\hline GDP at factor cost & 377.7 & 400.1 & 423.8 & 434.7 \\
\hline Import duties and fees & 9.0 & 10.8 & 12.4 & 13.5 \\
\hline \multirow[t]{2}{*}{ GDP at market price } & 386.7 & 410.9 & 436.2 & 448.2 \\
\hline & \multicolumn{4}{|c|}{ (Change in percentage from prior year) } \\
\hline Primary sector & 2.6 & 3.1 & 5.1 & 2.2 \\
\hline Agriculture, forestry, hunting and fishing & 3.2 & 3.3 & 3.0 & 3.0 \\
\hline Extractive industries & 0.9 & 2.5 & 11.4 & -0.2 \\
\hline Secondary sector & 8.5 & 5.1 & 3.0 & 1.8 \\
\hline Manufacturing industries & 0.9 & 5.1 & 2.7 & 2.1 \\
\hline Buildings and public works & 13.2 & 5.4 & 3.8 & 2.0 \\
\hline Electricity, water & 4.3 & 1.8 & -4.9 & -1.6 \\
\hline Tertiary sector & 9.0 & 11.1 & 8.3 & 3.5 \\
\hline Wholesale and retail trade & 8.9 & 13.1 & 12.3 & 6.5 \\
\hline Transportation and communications & 12.5 & 10.9 & 8.4 & 3.7 \\
\hline Goods and services & 7.5 & 6.9 & 4.8 & 2.7 \\
\hline Public services & 5.8 & 6.2 & 4.2 & -26.6 \\
\hline Imputed production of bank services & 14.8 & 13.0 & 110.3 & 4.0 \\
\hline GDP at factor cost & 5.4 & 6.0 & 5.9 & 2.6 \\
\hline Import duties and fees & 14.0 & 19.0 & 15.4 & 8.5 \\
\hline Real GDP & 5.6 & 6.3 & 6.2 & 2.8 \\
\hline
\end{tabular}

Source: Congolese authorities. 
Table 2 Democratic Republic of the Congo, Public Sector Financial Operations, 2006-09 (CDF Millions)

\begin{tabular}{rrrrrrr}
\hline & 2006 & 200 & & 2008 & 2009 & \\
\cline { 4 - 6 } & Est. & Est. & Est. & Est. & Prog \\
\hline
\end{tabular}

(Percentage of GDP; unless otherwise indicated

\begin{tabular}{|c|c|c|c|c|c|}
\hline $\begin{array}{l}\text { Total revenue and arants } \\
\text { Total fiscal and non-fiscal revenue } \\
\text { excludes Sino-Congolese arrangement }\end{array}$ & $\begin{array}{l}18.8 \\
12.8\end{array}$ & $\begin{array}{l}16.3 \\
14.7\end{array}$ & $\begin{array}{l}23.4 \\
18.5\end{array}$ & $\begin{array}{l}27.3 \\
18.0 \\
15.7\end{array}$ & $\begin{array}{r}21.3 \\
16.8 \\
15.8\end{array}$ \\
\hline Customs and excise (OFIDA) & 4.7 & 5.4 & 6.5 & 6.3 & 6.2 \\
\hline Direct and indirect contributions (DGI) & 3.8 & 5.0 & 6.6 & 6.4 & 6.2 \\
\hline Petroleum (royalties and taxes) & 3.2 & 3.1 & 3.5 & 1.4 & \\
\hline Other & 1.0 & 1.2 & 1.8 & 3.9 & \\
\hline Sino-Congolese arrangement & $\ldots$ & $\ldots$ & 0.0 & 2.3 & \\
\hline Other & & & & 1.6 & \\
\hline \multicolumn{6}{|l|}{ Revenue from China Mining project } \\
\hline Total grants & 6.0 & 1.6 & 4.9 & 9.4 & \\
\hline Budgetary grants & 1.0 & 0.0 & 0.0 & 2.7 & \\
\hline Project grants & 4.0 & 0.6 & 1.1 & 4.2 & 2 \\
\hline HIPC debt relief & 1.0 & 0.9 & 3.8 & 2.5 & 0.8 \\
\hline Total expenditure & 21.5 & 18.9 & 23.0 & 28.9 & 25. \\
\hline Current expenditure & 14.1 & 15.7 & 18.1 & 16.3 & \\
\hline Salaries & 5.3 & 5.8 & 6.9 & 6.3 & 6 \\
\hline Interest payable on debt & 3.5 & 3.8 & 3.4 & 3.3 & \\
\hline Of which: interest on external debt & 3.0 & 3.2 & 2.9 & 2.9 & 2. \\
\hline Of which: interest on domestic debt & & 0.6 & 0.5 & 0.4 & \\
\hline Subsidies and transfers & 2.1 & 2.2 & 3.5 & 3.0 & \\
\hline Economic interventions & 0.0 & 0.2 & 0.2 & 0.2 & \\
\hline Auxiliary organizations & 0.4 & 0.1 & 0.1 & 0.1 & \\
\hline Transfers to provinces & 0.8 & 1.0 & 1.9 & 1.6 & \\
\hline Payments to revenue-collecting agencies & 0.9 & 0.9 & 1.1 & 1.1 & \\
\hline Goods and services & 3.2 & 3.9 & 4.3 & 3.7 & \\
\hline Of which: Institutions & 0.5 & 0.9 & 1.2 & 0.9 & \\
\hline Ministries & 1.5 & 2.8 & 2.5 & 2.1 & 2. \\
\hline Centralized payment & $\begin{array}{l}0.6 \\
6.4\end{array}$ & 0.3 & 0.5 & 0.7 & \\
\hline Capital expenditures & 3.2 & 2.3 & 3.7 & 9.2 & \\
\hline External financing & 2.2 & 1.5 & 2.1 & 6.2 & \\
\hline Domestic financing & 1.0 & 0.9 & 1.6 & 2.9 & \\
\hline Central government investment & 1.0 & 0.9 & 1.6 & 1.6 & 1. \\
\hline Provincial investment & 0.0 & 0.0 & 0.0 & 1.3 & \\
\hline Exceptional expenditure 2/ & 4.2 & 0.9 & 1.2 & 3.4 & 2. \\
\hline External financing & 3.2 & 0.0 & 0.1 & 2.3 & \\
\hline \multirow[t]{2}{*}{ Domestic financing } & 1.0 & 0.9 & 1.1 & 1.2 & \\
\hline & & 0.0 & 0.0 & 0.1 & \\
\hline General balance (commitment basis) & -2.8 & -2.6 & 0.4 & -1.6 & \\
\hline \multirow[t]{2}{*}{ Domestic balance (commitment basis) } & 0.6 & 1.4 & 1.6 & -0.7 & \\
\hline & -0.4 & 0.5 & 0.5 & -1.9 & \\
\hline Variation in arrears & -0.2 & -0.2 & -0.2 & -0.6 & -0.5 \\
\hline Central bank balance & -0.5 & -0.4 & -0.5 & -0.9 & -0.9 \\
\hline Consolidated general balance & -2.9 & -3.2 & -0.4 & -3.0 & -5.9 \\
\hline Domestic balance & 0.5 & 0.8 & 0.9 & 0.1 & -0.1 \\
\hline Total financing & 2.9 & 3.2 & 0.4 & 3.0 & 5.9 \\
\hline Domestic financing & 1.1 & 0.9 & 0.9 & -0.8 & \\
\hline of which: Banking sector & 1.2 & 0.9 & 1.1 & -1.2 & -0 . \\
\hline External financing & 1.8 & 2.9 & -0.9 & 3.3 & \\
\hline Amortization payable before debt relief & -3.7 & -3.9 & -3.8 & -4.9 & \\
\hline Project loans & 1.3 & 1.2 & 0.8 & 4.6 & \\
\hline Debt relief & 3.5 & 3.8 & 0.7 & 0.3 & \\
\hline Cumulative external arrears & 0.7 & 1.8 & 1.4 & -6.4 & \\
\hline Financing gap & 0.1 & -0.6 & 0.5 & 0.6 & \\
\hline
\end{tabular}

Source: Congolese authorities. 
Table No. 1. Progress toward Millennium Development Goals in the DRC

\begin{tabular}{|c|c|c|c|c|}
\hline Objectives & Indicators used in DRC & $\begin{array}{l}\text { Value in } \\
1990\end{array}$ & $\begin{array}{l}\text { Value in } \\
2001\end{array}$ & $\begin{array}{l}\text { Value in } \\
2007\end{array}$ \\
\hline \multirow{5}{*}{$\begin{array}{l}\text { 1. Reduce extreme } \\
\text { poverty and hunger }\end{array}$} & Incidence of poverty & $60.0 \%$ & $73.0 \%$ & $71.34 \%$ \\
\hline & $\begin{array}{l}\text { Proportion of persons living on less than } \\
\text { US\$1 per day }\end{array}$ & $60.0 \%$ & $73.0 \%$ & $71.3 \%$ \\
\hline & Human development index & & & $41.1 \%$ \\
\hline & Proportion of underweight children & $28.0 \%$ & $34.0 \%$ & $25.1 \%$ \\
\hline & $\begin{array}{l}\text { Proportion of population consuming less } \\
\text { than the minimum caloric intake }\end{array}$ & $31.0 \%$ & $73.0 \%$ & \\
\hline \multirow{4}{*}{$\begin{array}{l}\text { 2. Universal primary } \\
\text { education }\end{array}$} & Net primary school enrollment rate & $56.0 \%$ & $52.0 \%$ & $62.0 \%$ \\
\hline & Gross primary school enrollment rate & & $64.0 \%$ & $83.4 \%$ \\
\hline & Primary school completion rate & $51.0 \%$ & $25.0 \%$ & $50.0 \%$ \\
\hline & Literacy rate & & & $75.0 \%$ \\
\hline \multirow{3}{*}{$\begin{array}{l}\text { 3. Promote equality of } \\
\text { the sexes and } \\
\text { empowerment of women }\end{array}$} & Ratio of girls/boys in elementary school & $74.0 \%$ & $90.0 \%$ & $78.0 \%$ \\
\hline & Ratio of girls/boys in secondary school & $45.0 \%$ & $54.0 \%$ & \\
\hline & Percent elected by gender ( $\%$ of women) & $6.0 \%$ & $10.3 \%$ & $8.4 \%$ \\
\hline \multirow{2}{*}{$\begin{array}{l}\text { 4. Reduce infant } \\
\text { mortality }\end{array}$} & Infant mortality rate & $\begin{array}{l}148 \text { of } \\
1,000\end{array}$ & 126 of 1,000 & 98 of 1000 \\
\hline & $\begin{array}{l}\text { Proportion of children under age } 2 \\
\text { vaccinated against measles }\end{array}$ & & & $62.9 \%$ \\
\hline \multirow{3}{*}{$\begin{array}{l}\text { 5. Improve maternal } \\
\text { health }\end{array}$} & Maternal mortality rate & 870 & 1289 & 549 \\
\hline & Proportion of attended births & & $60.7 \%$ & $74.0 \%$ \\
\hline & Prenatal care coverage (1995) & $56.0 \%$ & $68.2 \%$ & $85.3 \%$ \\
\hline \multirow{7}{*}{$\begin{array}{l}\text { 6. Combat HIV/AIDS, } \\
\text { malaria, and other } \\
\text { disease }\end{array}$} & Prevalence of HIV AIDS & nd & $\begin{array}{c}4.2 \% \\
(2003) \\
\end{array}$ & $\begin{array}{l}3.4 \% \\
(2009) \\
\end{array}$ \\
\hline & Use of contraceptives (all methods) & & $31.4 \%$ & $21.0 \%$ \\
\hline & Use of contraceptives (modern method) & $15.0 \%$ & $4.4 \%$ & $5.7 \%$ \\
\hline & Under-5 malaria mortality rate per 100,000 & $\ldots$ & $1000.0 \%$ & \\
\hline & Number of children orphaned by AIDS & & nd & 7000 \\
\hline & $\begin{array}{l}\text { Children under } 5 \text { protected by insecticide- } \\
\text { treated mosquito nets }\end{array}$ & & $0.7 \%$ & $6.0 \%$ \\
\hline & Incidence of tuberculosis & & & $\begin{array}{c}160 \text { of } \\
100,000\end{array}$ \\
\hline \multirow{6}{*}{$\begin{array}{l}\text { 7. Ensure environmental } \\
\text { sustainability }\end{array}$} & $\begin{array}{l}\text { Proportion of urban population with access } \\
\text { to potable water }\end{array}$ & & - & $38.0 \%$ \\
\hline & $\begin{array}{l}\text { Proportion of rural population with access } \\
\text { to potable water }\end{array}$ & $25.7 \%$ & $28.5 \%$ & $16.7 \%$ \\
\hline & $\begin{array}{l}\text { Proportion of urban population living in a } \\
\text { clean environment }\end{array}$ & & - & $9.0 \%$ \\
\hline & $\begin{array}{l}\text { Proportion of population with reliable } \\
\text { access to better-quality water }\end{array}$ & $41.5 \%$ & $45.7 \%$ & $22.1 \%$ \\
\hline & $\begin{array}{l}\text { Proportion of population with access to } \\
\text { sanitation services }\end{array}$ & $12.6 \%$ & $8.8 \%$ & $10.0 \%$ \\
\hline & $\begin{array}{l}\text { Proportion of rural population living in a } \\
\text { clean environment }\end{array}$ & $6.3 \%$ & $39.4 \%$ & $11.0 \%$ \\
\hline \multirow{2}{*}{$\begin{array}{l}\text { 8. Implement a global } \\
\text { partnership for } \\
\text { development }\end{array}$} & Completion rate for seven triggers & & - & Low \\
\hline & Proportion of APD in relation to GDP & & $\begin{array}{l}\text { Extremely } \\
\text { low }\end{array}$ & Very low \\
\hline
\end{tabular}

Source: EDS 2007; MICS 1, 2, 3; 1-2-3 Survey Sector statistics, MDG Report 2004 
Summary of actions implemented under the 2008-2009 Priority Action Plan

\begin{tabular}{|c|c|c|c|c|c|}
\hline No. & PILLARS & COMPLETED & $\begin{array}{c}\text { IN } \\
\text { PROGRESS }\end{array}$ & $\begin{array}{c}\text { NOT } \\
\text { COMPLETED (as } \\
\text { of April 2009) }\end{array}$ & $\begin{array}{l}\text { Actions } \\
\text { planned }\end{array}$ \\
\hline \multirow[t]{20}{*}{$\mathbf{I}$} & $\begin{array}{l}\text { PROMOTING GOOD GOVERNANCE AND } \\
\text { CONSOLIDATING PEACE THROUGH } \\
\text { INSTITUTIONAL STRENGTHENING }\end{array}$ & & & & \\
\hline & JUDICIAL AND SECURITY GOVERNANCE & & & & \\
\hline & Security & 0 & 1 & 6 & 7 \\
\hline & Justice & 12 & 7 & 11 & 30 \\
\hline & Police & 17 & 31 & 40 & 88 \\
\hline & Army & & & & 0 \\
\hline & Sexual violence & 10 & 1 & 0 & 11 \\
\hline & $\begin{array}{l}\text { POLITICAL AND ADMINISTRATIVE } \\
\text { GOVERNANCE }\end{array}$ & & & & \\
\hline & Public administration & 3 & 2 & 4 & 9 \\
\hline & Local governance & 2 & 1 & 6 & 9 \\
\hline & Election & 2 & 0 & 6 & 8 \\
\hline & ECONOMIC GOVERNANCE & & & & 0 \\
\hline & Transparency in public financial management & 0 & 0 & 15 & 15 \\
\hline & Debt management & 0 & 0 & 10 & 10 \\
\hline & Restructuring of statistical apparatus & 0 & 2 & 2 & 4 \\
\hline & Reform of public enterprises & 4 & 0 & 1 & 5 \\
\hline & Business climate & 0 & 0 & 0 & 0 \\
\hline & Jobs & 0 & 2 & 23 & 25 \\
\hline & Financial system reform & 6 & 7 & 4 & 17 \\
\hline & Subtotal (1) & 56 & 54 & 128 & 238 \\
\hline \multirow[t]{8}{*}{ II } & POLICIES SUPPORTING ECONOMIC GROWTH & & & & 238 \\
\hline & Agriculture and rural development & 0 & 0 & 0 & 0 \\
\hline & Forest and environment & 10 & 9 & 6 & 25 \\
\hline & Minds and Hydrocarbons & 2 & 5 & 11 & 18 \\
\hline & Energy & 18 & 27 & 14 & 59 \\
\hline & Transportation infrastructure & 14 & 22 & 17 & 53 \\
\hline & Industry & 10 & 6 & 26 & 42 \\
\hline & Subtotal (2) & 54 & 69 & 74 & 197 \\
\hline \multirow[t]{7}{*}{ III } & $\begin{array}{l}\text { ACCESS TO SOCIAL SERVICES AND REDUCING } \\
\text { VULNERABILITY }\end{array}$ & & & & \\
\hline & Education & 10 & 4 & 64 & 78 \\
\hline & Health & 51 & 18 & 49 & 118 \\
\hline & Water and sanitation & 3 & 4 & 32 & 39 \\
\hline & Social protection & 0 & 0 & 0 & 0 \\
\hline & Gender & 6 & 1 & 1 & 8 \\
\hline & Subtotal (3) & 70 & 27 & 146 & 243 \\
\hline \multirow[t]{2}{*}{ IV. } & Combating HIV/AIDS & 17 & 5 & 3 & 25 \\
\hline & Subtotal (4) & & & & 0 \\
\hline \multirow[t]{3}{*}{$\mathbf{V}$} & SUPPORT LOCAL INITIATIVES & 1 & 3 & 4 & 8 \\
\hline & Subtotal (5) & 1 & 3 & 4 & 8 \\
\hline & TOTAL $(1)+(2)+(3)+(4)+(5)$ & 198 & 158 & 355 & 711 \\
\hline
\end{tabular}

